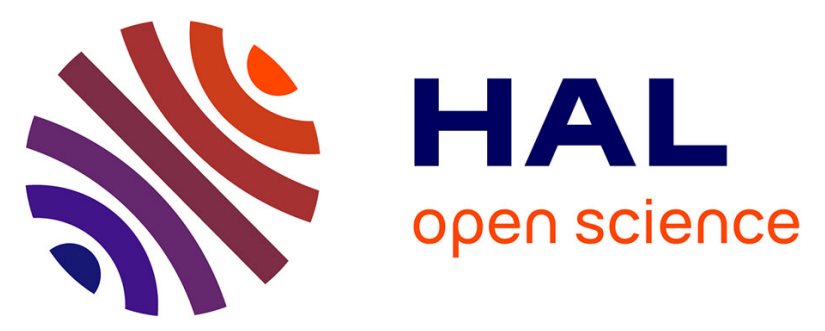

\title{
Broad-band 3-D earthquake simulation at nuclear site by an all-embracing source-to-structure approach
}

F Gatti, Sara Touhami, Fernando Lopez-caballero, D. Clouteau, V Alves

Fernandes, M. Kham, F. Voldoire

\section{- To cite this version:}

F Gatti, Sara Touhami, Fernando Lopez-caballero, D. Clouteau, V Alves Fernandes, et al.. Broadband 3-D earthquake simulation at nuclear site by an all-embracing source-to-structure approach. Soil Dynamics and Earthquake Engineering, 2018, 115 (1), pp.263-280. 10.1016/j.soildyn.2018.08.028 . hal-01859717

\section{HAL Id: hal-01859717 https://hal.science/hal-01859717}

Submitted on 22 Aug 2018

HAL is a multi-disciplinary open access archive for the deposit and dissemination of scientific research documents, whether they are published or not. The documents may come from teaching and research institutions in France or abroad, or from public or private research centers.
L'archive ouverte pluridisciplinaire HAL, est destinée au dépôt et à la diffusion de documents scientifiques de niveau recherche, publiés ou non, émanant des établissements d'enseignement et de recherche français ou étrangers, des laboratoires publics ou privés. 


\title{
Broad-band 3-D earthquake simulation at nuclear site by an all-embracing source-to-structure approach
}

\author{
F. Gatti ${ }^{\mathrm{a}, *}$, S.Touhami ${ }^{\mathrm{a}}$, F.Lopez-Caballero ${ }^{\mathrm{a}}$, R.Paolucci ${ }^{\mathrm{b}}$, D.Clouteau ${ }^{\mathrm{a}}$, \\ V.Alves Fernandes ${ }^{\mathrm{c}}$, M.Kham ${ }^{\mathrm{c}}$, F.Voldoire ${ }^{\mathrm{c}}$ \\ ${ }^{a}$ Laboratoire de Mécanique des Sols, Structures et Matériaux (MSSMat) UMR CNRS 8579 \\ 3, rue Joliot Curie, 91190 Gif-sur-Yvette (France) \\ ${ }^{b}$ Dipartimento di Ingegneria Civile e Ambientale (DICA) \\ P.zza Leonardo da Vinci 32, 20133 Milano \\ ${ }^{c}$ Electricité de France-REDD Department and IMSIA UMR EDF-CNRS-CEA-ENSTA 9219 \\ 7, Boulevard Gaspard Monge, 91120 Palaiseau
}

\begin{abstract}
The scope of this paper is to give an insight into the advantages of a new, allembracing, modeling approach of a strong ground motion scenario, by carrying out a source-to-structure analysis at regional scale, accounting explicitly for the uncertainties related to the databases and the models. To this end, a suitable case-study is represented by the 2007 Mw6.6 Niigata-Ken Chüetsu-Oki seismic sequence (west Japan), that damaged the Kashiwazaki Kariwa Nuclear Power Plant. This study describes the effect of the wave propagation path within the Earth's crust on the seismic response of nuclear reactor buildings located nearby a seismogenic source. The multiscale problem is de-coupled into three steps: (1) a parallel simulation of seismic-wave propagation throughout the Earth's crust at regional scale $(\approx 60 \mathrm{~km}$ wide, major 3 -D geological interfaces found below the nuclear site), reliable up to $5.0 \mathrm{~Hz}$; (2) a mid hybridization step consisting in enriching the synthetic wave-field at high frequency (up to $30 \mathrm{~Hz}$ ), employing an Artificial Neural Network to predict the short-period (SP) spectral ordinates; (3) a high-resolution structural dynamic analysis, introducing the hybrid broadband synthetics as input wave-motion. A simplified stress-test is performed,
\end{abstract}

\footnotetext{
Fully documented templates are available in the elsarticle package on CTAN

* Corresponding author

Email address: filippo.gatti@centralesupelec.fr (F. Gatti)
} 
by simulating two small point-wise aftershocks at different source-site position. The impact of the underground 3-D geology on the structural components is finally quantified, by injecting the obtained broad-band time-histories in a SoilStructure Interaction (SSI) model of the nuclear reactor building. The good fit obtained in terms of amplification factor at different recording stations assures the high-fidelity of the holistic philosophy endorsed.

Keywords: Earthquake Simulation, Artificial Neural Networks, SSI, nuclear reactor, vulnerability

2018 MSC: 00-01, 99-00

\section{Introduction}

\subsection{Synthetic simulation of 3-D earthquake ground motion from the fault to the} structure

The earthquake-related economic losses quickly raised to billion dollars in the last 25 years, due to population dynamics and growth which, in turn, led to the gradual decrease in the availability of safer lands, along with an increased susceptibility to excessive damage and low resilience, i.e. an inevitable increase of potentially dangerous places [1]. Therefore, scientists and regulators are progressively taking advantage of the ever-increasing computational power available, to embrace a holistic modeling strategy that couples the large scale seismological models for the region of interest (including the fault mechanism and the geological properties of the Earth's crust), with local engineering models for geotechnical, site-effect and structural analyses (see, for instance, the well established engineering method called Domain Reduction Method (DRM) [2, 3], the Micro-Macro Analysis Method (MMAM) [4, 5, 6]). To this purpose, one major challenge to be faced resides into the need to enlarge the accuracy of the numerical prediction at higher frequency, so to render a synthetic broad-band strong ground motion field across a wide region, as well as to reproduce the site response to the ground shaking. The reason stems essentially from the interest into a continuous coupling (in time and space) between the wave-propagation 
problem (typically referring to $0.0-10.0 \mathrm{~Hz}$ ) and structural vibrational problem (typically referring to $0.0-30.0 \mathrm{~Hz}$ ). As a matter of fact, the seismic design of buildings and infrastructures requires reliable (in terms of frequency content and duration) input ground motion to excite the most important vibrational modes and to study the degradation mechanisms. Moreover, most of the vulnerability studies are based on several earthquake Intensity Measures (IM), for instance Peak Ground Acceleration (PGA) and other indicators extremely sensitive to the high-frequency $(\mathrm{HF})$ content of the incident ground motion. However, the definition of suitable boundary conditions to inject the input ground motion (eventually including Soil-Structure Interaction, SSI) is still a matter of debate. On the other hand, seismological studies are struggling with the poor characterization of continental discontinuities and geological interfaces in the Earth's crust, which adds to the huge computational burden required to perform wave propagation/inversion studies in complex and large 3-D domains. In this sense, the largest frequency limit, at present, reached by a wave-propagation code is 18 $\mathrm{Hz}$, over a $320 \mathrm{~km}$ by $312 \mathrm{~km}$ by $40 \mathrm{~km}$ region [7], for the simulation of the 1976 Tangshan earthquake (China). The model has a spatial discretization varying between $500 \mathrm{~m}$ and $8 \mathrm{~m}$, interpolating a 3-D velocity model of north China with resolutions of $25 \mathrm{~km}$ in horizontal and of $1-2 \mathrm{~km}$ in the vertical directions includ-

40 ing the sediment structures. However, the current trend among analysts ranges around 2.0-5.0 Hz [8, 9], shifting progressively towards $10 \mathrm{~Hz}$ [10], for regions spanning tens/hundreds of kilometers (see for instance the broad-band platform developed within the framework of the Southern California Earthquake Center, SCEC [1]]). This trend is expected to increase in the very near future, owing the seemingly unstoppable growth of the High-Performance Computing (HPC) resources (towards exascale engineering simulations [12]). In the meanwhile, and alternatively, broad-band synthetic ground motion prediction can be obtained by hybrid modeling: starting from an idea of Graves and Pitarka [13], the highfidelity low-frequency (LF) part of the simulated ground motion is sealed at each station with stochastic or empirical prediction at high frequencies, to cope with the intrinsic poor accuracy of numerical physics-based analysis methods 
employed to simulate the HF part of the synthetic wave-forms.

\subsection{TheSINAPS@ project}

In this context, after the 2011 Fukushima accident, the SINAPS@ project associated to databases, physical processes and methods used at each stage of seismic hazard, site effects, soil and structure interaction, structural and nuclear components vulnerability assessments, in a safety approach: the main objective is ultimately to identify the sources of potential seismic margins resulting from assumptions or when selecting the seismic design level or the design strategy.

SINAPS@ represents the first ever French national research program aiming at reviewing and updating the current seismic design standards of nuclear facilities on French territory, by embracing a continuous source-to-structure approach [14]. SINAPS@ unravels into multiple work-packages, animated by a unique yet manifold goal [14]: to review (1) the traditional and current experimental and numerical approaches to investigate an earthquake phenomenon and (2) to design the structural response to a ground shaking, by employing a rigorous uncertainty quantification routine at each modeling stage and to all the input parameters and related databases [15]. One major goal of the SINAPS@ research team is to develop a High-Performance (HP) and portable multi-tool computational platform, capable of dealing with the manifold nature of an earthquake phenomenon itself, i.e. spanning from the simulation of the source mechanisms, to the reproduction of the heterogeneous and non-linear rheology of the geomaterials within the Earth's crust domain and the soil deposits, to the presence of surface/buried topography as well as of the ocean's bathymetry and finally to the interaction with the buildings and the structural components. This endeavor is accompanied by a rigorous yet necessary verification and validation phases, in order to grant a high-fidelity prediction [see the guidance provided by [16]. In spite of the inherent complexity and of the

${ }^{1}$ https://www.institut-seism.fr/projets/sinaps/ 
multi-scale nature of those large yet refined 3-D computational models, their power is essentially embodied by the higher broad-band accuracy they provide. However, one major open challenge consists into including the structural components within the overall computational framework, gradually bridging the gap between LF source models obtained via wave-form inversion techniques and the structural modal frequencies (i.e. up to $30.0 \mathrm{~Hz}$ ).

\subsection{Outline of the paper}

In this paper, the construction of a 3-D broad-band Source-to-Structure (BBS2S) earthquake scenario is presented. Specifically, the paper refers to the study of the seismic site response of the Kashiwazaki-Kariwa Nuclear Power

90 Plant (KKNPP, owned by the Tokyo Electric Power Company, TEPCO), during the Mw6.6 2007 Niigata-Ken Chūetsu-Oki earthquake (NCOEQ-2007). Figure 1shows a map of the epicentral area (approximately $60 \mathrm{~km}$ wide) along with the three asperities outlined by Shiba et al. [17]. The synthetic structural re-

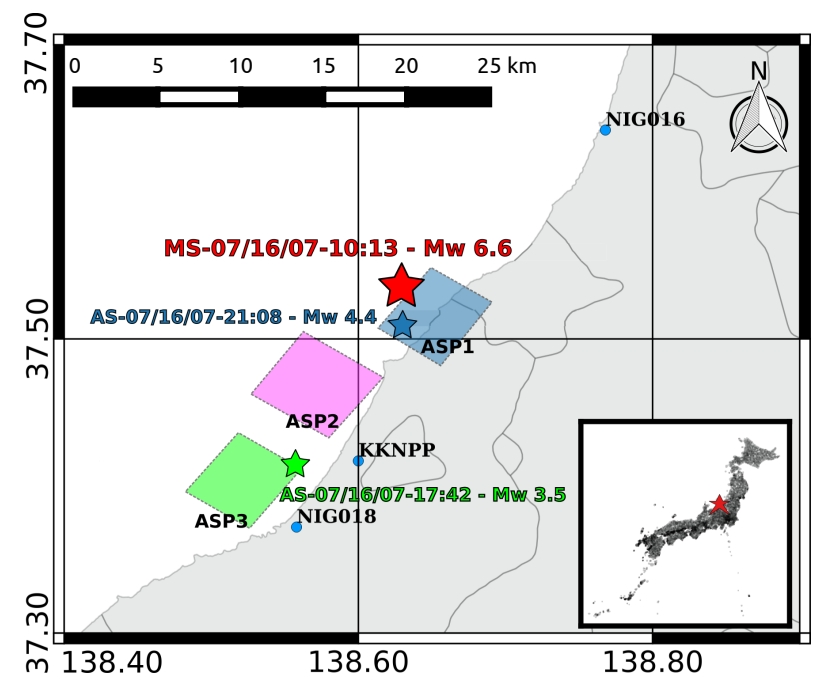

Figure 1: Map of the Niigata region, surrounding the KKNPP (black square). The NCOEQ2007 main shock epicenter is indicated as a red star, whereas colored squares indicate the relocated aftershocks positions [18]. ASP1, ASP2 and ASP3 indicate the three major asperities deducted by Shiba et al. [17], by means of wave-form inversion. 
sponse is obtained by a multi-step analysis work-flow. In this regard, this paper

95 is an extension of the previous work presented by Quinay et al. 6]. The authors performed a fault-to-structure two-step numerical simulation for the same applicative case, supplied by verification and validation tests with application to maximum target frequency of $1.0 \mathrm{~Hz}$. The regional model has provided near surface free-field wave motion, employed in a following stage to compute the dynamic responses of the building structure within the nuclear power plant, using a fine-resolution model based on realistic conditions. In this study, the regional scale 3-D earthquake scenario is at first calibrated up to $5.0 \mathrm{~Hz}$ [8], exploiting a 3-D spectral-element based software and including the complex folding geology described by several authors, as for instance [19, 20] (see Section 3). Two aftershocks are simulated, by prepartitioning the computational domain over a distributed-memory supercomputer. Compared to Quinay et al. [6], a extra mid-step is added herein: the seismic wave-field rendered by the regional scale analysis is enriched at $\mathrm{HF}$ (up to $30.0 \mathrm{~Hz}$ ) by applying the so called ANN2BB hybrid procedure, introduced by [21] and based on the use of Artificial Neural Networks to predict the short-period (SP) part of the pseudo-acceleration response spectra $S a$. This hybridization step is described in Section 2.3.3. Finally, the hybrid broad-band synthetics are injected as input motion into a SSI structural model of the reactor building at Unit 7 at the KKNPP (RB7) 22]. The simulated structural response is compared to the recorded one, see [23].

\section{Data and methods}

\subsection{Unwrapping a complex earthquake scenario: the case of NCOEQ-2007}

This paper focuses on the seismic response of the Japanese nuclear site of Kashiwazaki-Kariwa. A map of the KKNPP site is shown in Figure 2, KKNPP was damaged by the NCOEQ-2007, although no catastrophic failures occurred.

${ }_{120}$ The ground shaking interested an area of approximately $100 \mathrm{~km}$ of radius along the coastal line of South-West Niigata prefecture, till a maximum depth of 


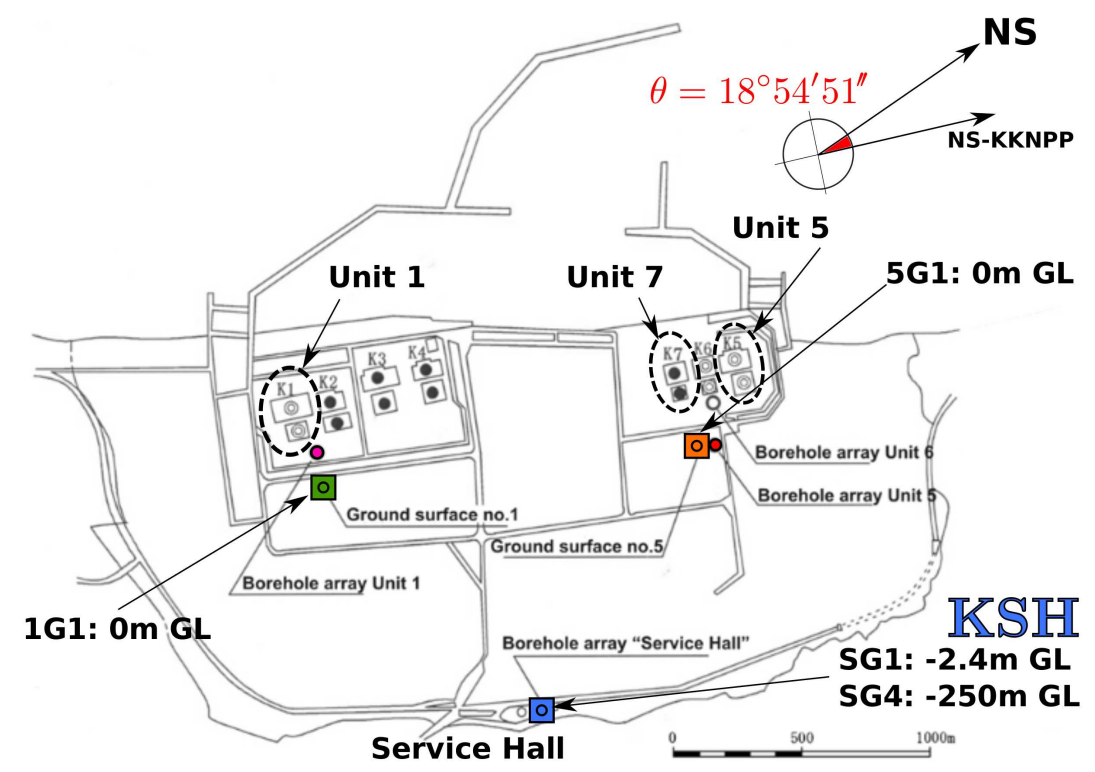

Figure 2: Map of the KKNPP site 18] (courtesy of TEPCO). The five coloured squares indicate the three recording stations downhole (KSH at Service Hall (blue) and the two surface ones free-field (1G1 at Unit 1 (green) and 5G1 at Unit 5 (orange)). The devices were oriented with respect to plant North (NS-KKNPP), which differs from the real geodetic North of an angle $\theta=18^{\circ} 54^{\prime} 51^{\prime \prime}$. Instrumental azimuthal deviation [18] was corrected. 
$17 \mathrm{~km}$ 24]. The plant consists of 7 reactor buildings (see map in Figure 21) and it is located on the hanging wall of the seismogenetic fault that triggered the NCOEQ-2007 event. The strong motion sensors indicated that during the main shock the site experienced nearly twice the Peak Ground Acceleration (PGA) considered at the plant design. Moreover, the rather high variability of PGA values within the site area is representative of directivity features of the source radiation (see 24] and [25] for an extensive review of the observed recordings and site-effect reconnaissance). The KSH downhole array (see map in Figure 21), along with recording devices at surface 1G1 and 5G1 entirely recorded the NCOEQ-2007 main shock. Unit 7 is located on the NE part of the site, near Units 5 and 6 . Unit 7 Reactor Building (RB7) was instrumented both at the foundation level (7-R2) and at the third floor (7-R1) [23, 26]. The Unit 7 Reactor Building (RB7) is $63 \mathrm{~m}$ high, although $26 \mathrm{~m}$ are buried [22], therefore directly reposing over the Nishiyama rock formation (see Figure 5a ). During the NCOEQ-2007, the RB7 was very slightly damaged, leading to considering its transient behaviour within the linear elastic framework [23, 26].

\subsection{Construction of the regional scale scenario}

The subsurface geological structure underlying the Niigata region has been proven to be rather intricate. The authors [8] recently performed a 3-D largescale earthquake simulation in the KKNPP surroundings (Figure 3a), accurate up to $5 \mathrm{~Hz}$, based on the previous works of [19, 20]. The authors tested and calibrated a hybrid buried geological structure, composed of:

- the 1-D layered geological model proposed by Aochi et al. [27], representative for the propagation of the long-period (LP) ground motion (i.e. 0.1-3.75 Hz) at a regional scale (see the velocity and attenuation properties listed in Table 1);

- the 3-D folding conformation, known as the 3-D Ushirodani anticline Madonosaka syncline - Chuo-Yatai anticline structure (widely described in [19, 20], and whose cross section (referred as to $S C$ ) is portrayed in 
Figure 3b), placed right underneath the KKNPP site (Table2]summarizes the mechanical properties assumed in this paper for the folding crosssection $S C$, firstly proposed by $[19,28,20])$.

The final 3-D immersed geological model (depicted in Figure 3c) takes into account the propagation of the regional wave-field, yet focusing on a realistic broad-band simulation of the incident ground motion in the KKNPP surroundings (i.e. an area of approximately $68 \mathrm{~km} \times 50 \mathrm{~km} \times 50 \mathrm{~km}$ ). Further details Table 1: Properties of the Aochi2013 profile 27]. $z$ represents the depth of the upper layer surface, $V_{P}$ and $V_{S}$ are the P-wave and S-wave velocities respectively, $Q_{P}$ and $Q_{S}$ the quality factors for P-wave and S-wave respectively. The * indicates the interface chosen to plug the folding structure into the 1-D Aochi2013 profile, granting a smooth transition from one model to the other.

\begin{tabular}{ccccc}
\hline$z[\mathrm{~km}]$ & $V_{P}[\mathrm{~km} / \mathrm{s}]$ & $Q_{P}[1]$ & $V_{S}[\mathrm{~km} / \mathrm{s}]$ & $Q_{S}[1]$ \\
\hline 0.0 & 2.28 & 200.0 & 1.02 & 100.0 \\
0.5 & 2.57 & 228.7 & 1.23 & 100.0 \\
1.0 & 2.93 & 257.1 & 1.51 & 100.0 \\
1.5 & 3.09 & 293.3 & 1.63 & 100.0 \\
2.0 & 3.25 & 309.1 & 2.09 & 100.0 \\
3.0 & 3.68 & 325.9 & 2.33 & 100.0 \\
4.0 & 4.03 & 368.2 & 2.49 & 100.0 \\
$\star 5.0$ & 4.30 & 403.2 & 2.75 & 100.0 \\
6.0 & 4.55 & 430.9 & 2.89 & 100.0 \\
7.0 & 4.76 & 455.8 & 3.10 & 100.0 \\
8.0 & 5.00 & 476.4 & 3.40 & 100.0 \\
9.0 & 5.37 & 500.2 & 3.76 & 100.0 \\
10.0 & 5.88 & 537.5 & 3.80 & 100.0 \\
14.0 & 6.51 & 588.7 & 3.85 & 250.0 \\
\hline
\end{tabular}

concerning the construction of the geological model and its calibration can be found in $[8]$. 


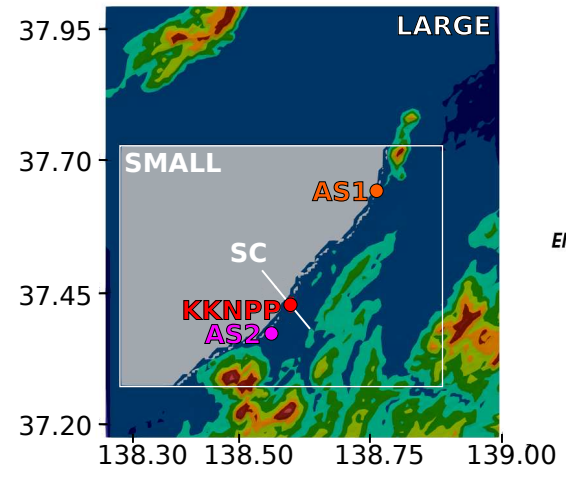

(a)

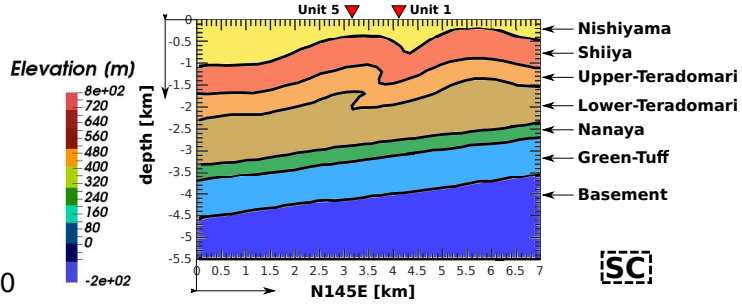

(b)

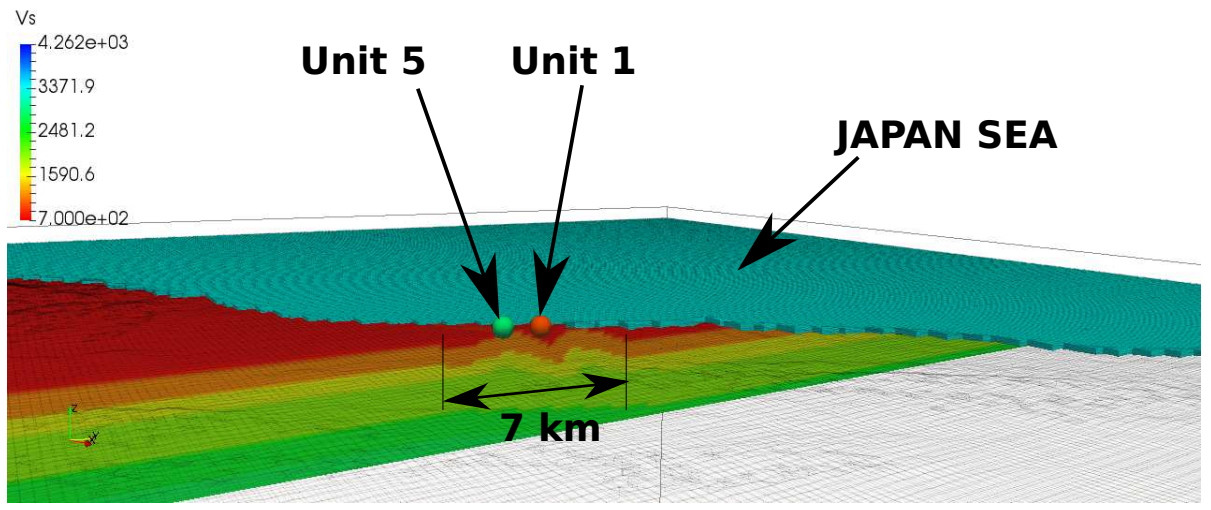

(c)

Figure 3: (a) Sketch of the extension of the computational models constructed by [8] (LARGE, for the regional wave-field and SMALL, focusing on the KKNPP local geology). Red, orange and fuchsia points indicate the KKNPP site and the epicenters of two aftershocks (AS1 and AS2 respectively) studied by [8]. The white line represents section SC, central reference geological cross-section, used for the extrusion of the folding model [8]. (b) Schematic structural map of the series of Ushirodani anticline - Madonosaka syncline, located underneath KKNPP.

(c) Section of the SEM3D mesh employed in this study, including the complex geology and the Japan sea. 
Table 2: Geological properties of the folding structure underneath KKNPP. $V_{P}$ and $V_{S}$ are the pressure- and shear-wave velocities respectively. The ${ }^{\star \star}$ indicates the interface chosen to plug the folding structure into the original 1-D Aochi2013 profile, granting a smooth transition from one model to the other.

\begin{tabular}{rccc}
\hline Layer & $V_{S}[\mathrm{~m} / \mathrm{s}]$ & $V_{P}[\mathrm{~m} / \mathrm{s}]$ & $\rho\left[\mathrm{Kg} / \mathrm{m}^{3}\right]$ \\
\hline Nishiyama & 700 & 1900 & 1700 \\
Shiiya & 1200 & 2200 & 2100 \\
Upper Teradomari & 1700 & 3300 & 2300 \\
Lower Teradomari & 2000 & 4200 & 2400 \\
Nanatani & 2000 & 4600 & 2500 \\
$\star \star$ Green tuff & 2600 & 5200 & 2600 \\
Seismic bed rock & $2600->2750$ & 5200 & 2600 \\
\hline
\end{tabular}

\subsection{Forward Numerical modeling of fault-to-site earthquake scenario}

The simulation of realistic ground shaking scenarios requires a reliable estimation of several different parameters, related to the source mechanism (extended fault or localized double-couple seismic moment, to the geological configuration and to the mechanical properties of the soil layers and crustal rocks. Due to the large extension of those regional scale scenarios, the degree of uncertainty associated to the whole earthquake process (from fault to the site) is extremely large, which eventually increases at higher frequencies and when the structural models are included. Another drawback lies in the computational effort required to routinely solve the wave propagation on such huge domains and over such a large number of DOFs (Degrees of Freedom). At this point, it appears necessary to build up a multi-tool numerical platform to construct and calibrate the seismological model. To this end, three main issues must be tackled:

1. to mesh the domain of interest, its geological conformation (bedrock to sediment geological surfaces), the surface topography and the bathymetry (if present) 
2. to describe the natural heterogeneity of the Earth's crust and soil properties, at different scales (i.e., regional geology, local basin-type structures and heterogeneity of granular materials, soil rheology and relevant constitutive relations)

3. to couple the wave-propagation problem with the structural dynamic problem represented, in this case, by the vibrational behaviour of the reactor building.

\subsubsection{Numerical tools and HPC resources involved}

Figure 4 outlines the features of the multi-tool platform developed within the framework of the SINAPS@ project. To respond to those needs, among the

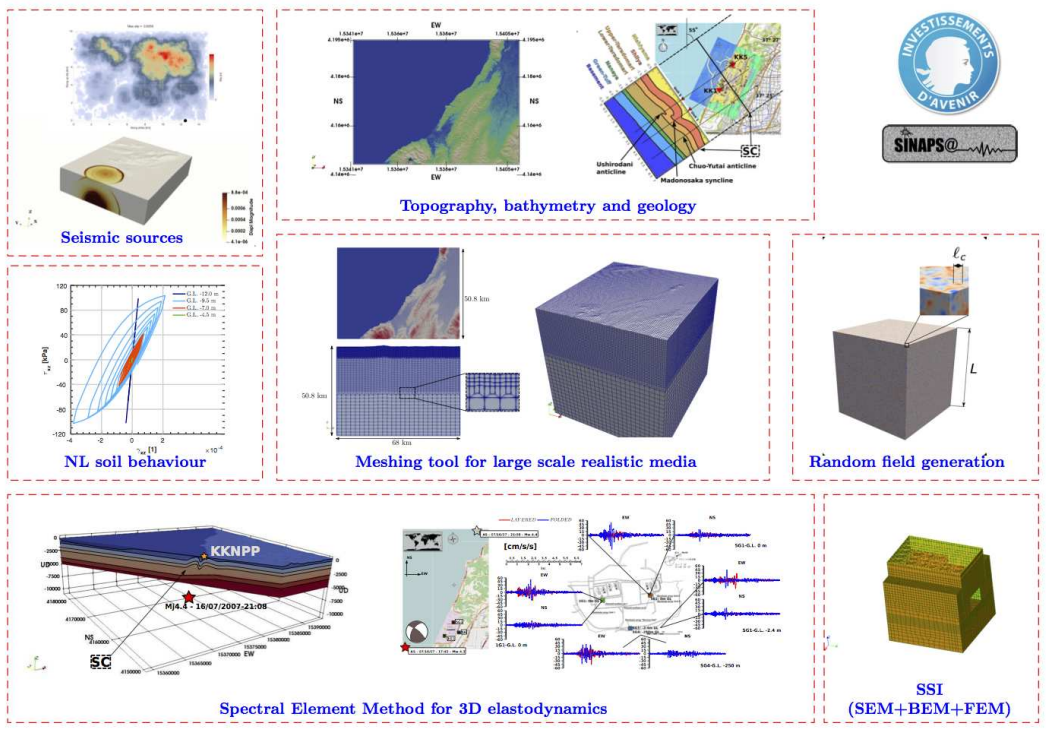

3D simulation of source-to-site earthquake scenario - SINAPS@ (ANR-11-RSNR-0022-04)

Figure 4: Schematic portray of the multi-tool platform developed within the SINAPS@ project to reproduce realistic source-to-structure seismic scenarios.

tools employed hereafter, the main wave propagation solver is represented by a software called SEM3D, tailored to efficiently solve the wave propagation problem, by means of the Spectral Element Method 29, 30. (see further details in Appendix C). SEM3D has been developed based upon the RegSEM code [31, 32]. The 
SEM (see Appendix C) is a high-order version of the Finite Element Method (FEM) and it has recently become predominant due to its accuracy and straightforward extension to parallel implementation, and it is well known to provide an accurate solution of the elasto-dynamic problem in highly heterogeneous media $[33,34,35]$. The original core of the SEM3D software allowed to solve the viscoelastic wave propagation problem in any velocity model, including anisotropy, intrinsic attenuation and Newtonian fluid-structure interaction. Moreover, the code makes use of a library called HexMesh 2 , that implements an efficient linear 27-tree finite element mesh generation scheme [35] and it is capable to generate large computational grids (i.e. $\approx 100 \mathrm{~km}$ ) by extruding the Digital Elevation Model (DEM) provided and progressively top-down coarsen it, so to obtain a non-structured grid. HexMesh easily handles coastlines and bathymetries, by cutting and locally refining the generated grid accordingly. The geological interfaces were introduced by a not honouring approach, which means the transition between geological domains is obtained by linearly interpolating the spatially distributed mechanical properties on the integration points used for the spectral approximation.

The 3-D FEM elastic structural model of the reactor building of Unit 7 was constructed by using code_aster $[36]^{3}$. The structural model was issued from the technical details provided by TEPCO in connection with the 2009 benchmark KARISMA (KAshiwazaki-Kariwa Research Initiative for Seismic Margin Assessment), organized under the auspices of the International Atomic Energy Agency (IAEA) and of the Nuclear Energy Agency (NEA), a specialised agency within the Organisation for Economic Co-operation and Development (OECD) 215 (see [23]). The seismic response of the reactor building is presented in details in [37].

\footnotetext{
${ }^{2}$ https://github.com/jcamata/HexMesh.git

3 www.code-aster.org
} 


\subsubsection{Two-stage weak coupling framework}

In order to obtain the free-field acceleration time-history next to RB7, the standard approach (26]) is based on the deconvolution of a signal recorded D.1). In the present case, the incident wave-motion is directly simulated by the SEM3D numerical simulation instead. The wave-propagation and transient structural dynamics model were interfaced by introducing compatible kinematic boundary conditions at the edge of the FEM model (see Section 5 for further details), whose impedance matrix functions have been previously computed by employing MISS3D [38], a Boundary Element Method (BEM) software in the frequency domain, that exploits the Green's functions of a layered semi-infinite half space, without requiring any additional mesh. In this study, viscoelastic, homogeneous and isotropic soil layers were considered. The BE method is used in the far field, the FEM mesh is restricted to the building. It can be applied to infinite domains, avoiding any reflection on fictitious borders truncating the domain of study [39].. Figure [5b portrays the described two step coupling scheme.

\subsubsection{The ANN2BB hybrid mid-step}

Owing to the limitations posed both by computational constraints and by insufficient knowledge of the medium at short wavelengths (i.e. the mesh size and the poor description of the fault mechanism and geology) physics-based simulations of the earthquake mechanism are regarded as reliable in the LP range (typically for natural periods $T>T^{\star}=0.75-1 \mathrm{~s}$ ). Figure 6a shows a typical pseudo-acceleration response spectra $S a$ for PBS (blue line), with evident numerical dispersion at SP, compared to the stochastic/empirical $S a$ prediction (STO/EMP, red line, obtained by several alternative approaches, as for instance [40]). Hybrid broad-band wave-form (black-dashed $S a$ spectrum), ob245 tained for instance with the method proposed by [13], are directly exploitable as spectrum-compatible input motions for seismic design of aboveground struc- 
tures. Although realistic at the single station, the STO/EMP prediction fails in rendering the spatial distribution of the HF IMs (i.e. PGA). To cope with these limitation, Paolucci et al. 21] proposed to make use of Artificial Neural Networks (ANN), trained on a set of strong motion records, to predict the response spectral ordinates at short periods, using as input the LP ones obtained by the PBS (blue $S a$ spectrum in Figure6a), and, then, to enrich the PBS timehistories by scaling iteratively their Fourier spectrum the ANN target spectrum (in small axes in Figure 6b). Further technical details on this so called ANN2BB procedure are outlined in [21].

Compared to a standard hybrid approach, ANN2BB yields realistic waveforms, both in time and frequency domains, as well as it renders maps of short-period peak values of ground motion which reproduce more closely the coupling of source-related and site-related features of earthquake ground motion. The approach is suitable to portray in a realistic way the spatial correlation features of the peak values of ground motion although it is not suitable yet to obtain sets of waveforms with realistic spatial coherency features at high frequency. Another issue to be deemed is the choice of the training dataset to be fairly representative of the earthquake process at hand.

\section{Broad-band numerical simulation of NCOEQ-2007 scenario}

Gatti et al. 8] simulated the site-response of KKNPP site for two aftershocks AS1 and AS2 (see Figure 3a). The hypocenters are located along the direction of the Madonosaka syncline, at the two opposite sides with respect to its planar cross-section passing through the TEPCO facility (see Table 3). The SEM3D

Table 3: Summary of the aftershock parameters employed in this analysis. $\left(\phi_{S} ; \lambda ; \delta\right)$ represents the strike, rake and dip angles estimated by F-NET Centroid Moment Tensor solution [42].

\begin{tabular}{ccccc}
\hline Event & $\mathrm{M}_{\mathrm{JMA}}$ & $\mathrm{M}_{0}[\mathrm{Nm}]$ & $\left(\phi_{S} ; \lambda ; \delta\right)\left[^{\circ}\right]$ & $\tau_{R}[\mathrm{~s}]$ \\
\hline AS1 $(07 / 16 / 07-21: 08)$ & 4.4 & $52.1 \cdot 10^{14}$ & $187 ; 70 ; 54$ & 0.113 \\
$\operatorname{AS} 2(07 / 16 / 07-17: 42)$ & 4.2 & $2.09 \cdot 10^{14}$ & $309 ; 78 ; 37$ & 0.045 \\
\hline
\end{tabular}


model employed for those simulations is featured by $\approx 2.010^{6}$ elements, with $7 \times 7 \times 7$ Gauss-Lobatto-Legendre integration points each. Further details on model accuracy and details are presented in [8]. Those simulations discounted the results from the effect of the finite-fault characteristics, highlighting the effects of the complex buried topography described in Section 2.2 and whose properties are listed in Table 2, To achieve this result, the aftershocks were considered as point-wise double-couple sources (see [30, 43]). Figures 7 and Figures 8 portray the pseudo-spectral acceleration spectra $S a$ (5\% damping) estimated at KKNPP, for AS1 and AS2 respectively. In these figures, the effect of the 3-D geology (FOLDED embodied by the blue $S a$ spectra) is compared to the simplified of a sub-horizontally layered geology ( $L A Y E R E D$, embodied by the red $S a$ spectra).

The outcome of the analysis is in good agreement with previous results (such as [44]). The large amplitudes simulated at Unit 1 (located on the synclinal axis, on the southwestward part of the KKNPP) is seemingly due to its relative position with respect to the folding structure. Figures 78 highlights that the interaction between impinging wave-field and folding structure entails a ground motion amplification nearby Unit 1 , for natural periods $T<0.5 s$, whereas the site response looks unaltered at Unit 5 and at the KKNPP Service Hall. The model do not include the site geology, but the minimum shear velocity corresponds to the engineering bedrock at depth. This aspect strengthens that the spatial incoherence of the earthquake ground motion at surface is influenced by the syncline-anticline structure, netting the non-linear site effects characterizing the borehole scale (and described in [25]). Moreover, the amplification at surface (emphasized along the EW direction) rendered by the analyses is independent of the source position. The study [19] showed that the Upper Teradomari stratum does not alter the wave-propagation of up-going waves, which tend to focalize at the Madonosaka syncline passing through Shiiya stratum. Site amplification becomes therefore significant at Unit 1. On the other hand, Unit 5 (which is located above the Ushirodani anticline) is evidently more sensitive to wave-motion travelling from South-West to North-East, throughout the 
folding zone: the pseudo-spectral peaks differs from layered to folded geology only in Figure 8 referring to AS2 (nucleated close by the third asperity on the fault rupture plane).

It is worth mentioning that the described geological model has a minimum shear-wave of $700 \mathrm{~m} / \mathrm{s}$, which represents the downhole engineering bedrock at depths below 150-250 m by TEPCO site characterization. The uppermost soil layers (Nishiyama, Yasuda, Banjin strata) are softer layers, which underwent major non-linear shearing effects during the NCOEQ-2007 main shock. The mesh designed herein was not able to render such a finer geological description, concurring at the discrepancies between the recordings and the synthetics.

\section{ANN2BB application to KKNPP numerical simulation}

The earthquake ground motion simulations performed in [8] are reliable up to $5 \mathrm{~Hz}$. Although outstanding, this twofold modeling and computational endeavour is hereafter extended towards broader-band prediction, aiming at exploiting broad-band synthetics in further SSI studies. The jump from 5 to $30 \mathrm{~Hz}$ is performed by applying the ANN2BB procedure described in Section 2.3.3. Before applying the ANN2BB procedure to the LP synthetic wave-motion, suitable ANN are trained. The outcome of the training session presented in Section 4.1 outlines the major steps of the ANN training phase, specifically targeting the choice of the corner period $\mathrm{T}^{\star}$.

\subsection{Designing and training $A N N$ on broad-band recordings}

In most cases, Artificial Neural Networks are used to estimate the non-linear relationship between a vector of input variables (herein the set of $N_{S a}^{L P} \mathrm{LP}$ spec325 tral ordinates, corresponding to $T \geq T^{\star}$, obtained via numerical simulation) and the output target (herein the $N_{S a}^{S P}$ SP spectral ordinates, corresponding to $\left.T<T^{\star}\right)$. In this study, the teaching dataset is represented by the SIMBAD database [45], consisting of $N_{d b}=501$ three components high-quality accelerograms recorded world-wide, spanning a range of $\mathrm{M}_{W}$ from 5 to 7.4 and epicentral 

set (refer to 21] for details on the training process and generalization features), one referring to the geometric mean of the horizontal components and one to the vertical one. In our case, the neural network is designed as a feed-forward two-layers Perceptron [46, 47], featured by $N_{n}^{h}=30$ sigmoid hidden neurons and of input variables $N_{S a}^{L P}$, whereas the number of nodes in the output layer $N_{n}^{o}$ equals the number of target values $N_{\mathcal{S}_{0}}^{S P}$. The ANNs were trained by exploiting the Levenberg-Marquardt algorithm [48, 49] to perform back-propagation of the error and adjust the weight:4 (see [21] for further details).

\footnotetext{
${ }^{4}$ At this stage, the neural network fitting tools (nftool) implemented in Matlab is used. MATLAB is available at https://fr.mathworks.com/solutions/deep-learning.html (last accessed March 2018).
} 
trained with two different corner periods $T^{\star}$. The ratio between estimated $\left(S a_{A N N}\right)$ and recorded $\left(S a_{R E C}\right)$ spectral values at $\mathrm{SP}$ are presented in the bottom rows of both Figure 9 and Figure 10. Although it is not possible to distinguish the spectral region where the deterministic nature of the seismic scenario plays a major role on the spectral shape, the choice of $T^{\star}=1 \mathrm{~s}$ (theoretically corresponding to an upper frequency of $1 \mathrm{~Hz}$ of the numerical simulations) seems quite inappropriate for both the Japanese and Italian earthquake considered (not present in the SIMBAD database). The increased predictive performance is evident when considering a lower $T^{\star}$.

\subsection{Applying ANN2BB to LF numerical simulations of NCOEQ-2007 scenario}

Despite the good fit between the SEM3D numerical simulations and the observations, and the high accuracy obtained at $5.0 \mathrm{~Hz}$, it is interesting to apply the ANN2BB technique to the synthetic time-histories obtained. For the sake of clarity, AS1 was solely presented. An ANN was trained with corner period $T^{\star}=0.75 \mathrm{~s}$, and applied to the numerical results obtained either with LAYERED geology or FOLDED geology (see Section3). To compare the accuracy obtained by either including or not the folding structure underneath KKNPP, Figures 11 portrays the site response (in terms of $S a$, with $5 \%$ damping) at 375 stations SG1 (Service Hall, G.L. -2.7 m, Figures 11c- 11a) and for 1G1 (Unit 1, G.L. 0 m, Figures 11d, 11b respectively. Figure $11 \mathrm{c}$ and Figure $11 \mathrm{~d}$ refer to the results obtained by applying ANN2BB to time-histories obtained via SEM3D with the LAYERED geology. On the other hand, Figure 11a and Figure $11 \mathrm{~b}$ refer to the results obtained by applying ANN2BB to time-histories obtained via SEM3D with the FOLDED geology. The improved prediction in a broad-band frequency range is evident, compared to SEM3D analyses, for both LAYERED and FOLDED geologies. The inclusion of a complex 3-D geology improves the match of recorded spectral amplitudes, specifically the predominant $S a$ peak. Therefore, it is evident that feeding the ANN2BB procedure with the seismic wave-motion obtained by a refined site-specific numerical analysis (including the folding structure) improves the overall broad-band prediction of 
the outcropping wave-motion. Figure 12 shows the ANN2BB time-histories (in a $0.1-30 \mathrm{~Hz}$ frequency range) which were exploited as synthetic input wavemotion for the structural model of the Unit 7 reactor building (see Section 5). In Appendix B. Fourier's spectra are shown (Figure B.15). The improved outcome of the broad-band synthetics obtained by ANN2BB confirms somehow the fact that the predictive methodology inherits the information concerning spatial distribution of the earthquake ground motion and it propagates it to shorter periods. This is an interesting phenomenon, since it proves the exceptional capability of neural networks to recognize the input pattern and predict the outcome based on the experience gained during the training phase. Even when SEM3D analyses provided poor fit to the records (probably due to the effect of shallow geotechnical layers, not considered in the 3-D numerical analyses at regional scale), the ANN2BB provides more reasonable spectral ordinates, recommending its utilization to generate realistic broad-band synthetics. It has to be noted again that the ANN employed at this stage were trained upon the SIMBAD database [45], containing high-quality recordings observed for earthquakes in a magnitude range $\mathrm{M}_{W}$ 5.0-7.5. Despite the fact that AS1 has a magnitude $\mathrm{M}_{W} 4.4$, the satisfactory results obtained ensure somehow the reliability of the ANN predictive capabilities.

It is reasonable to disregard the non-linear site-effects occurred during the main shock, since two small aftershocks were solely considered. 


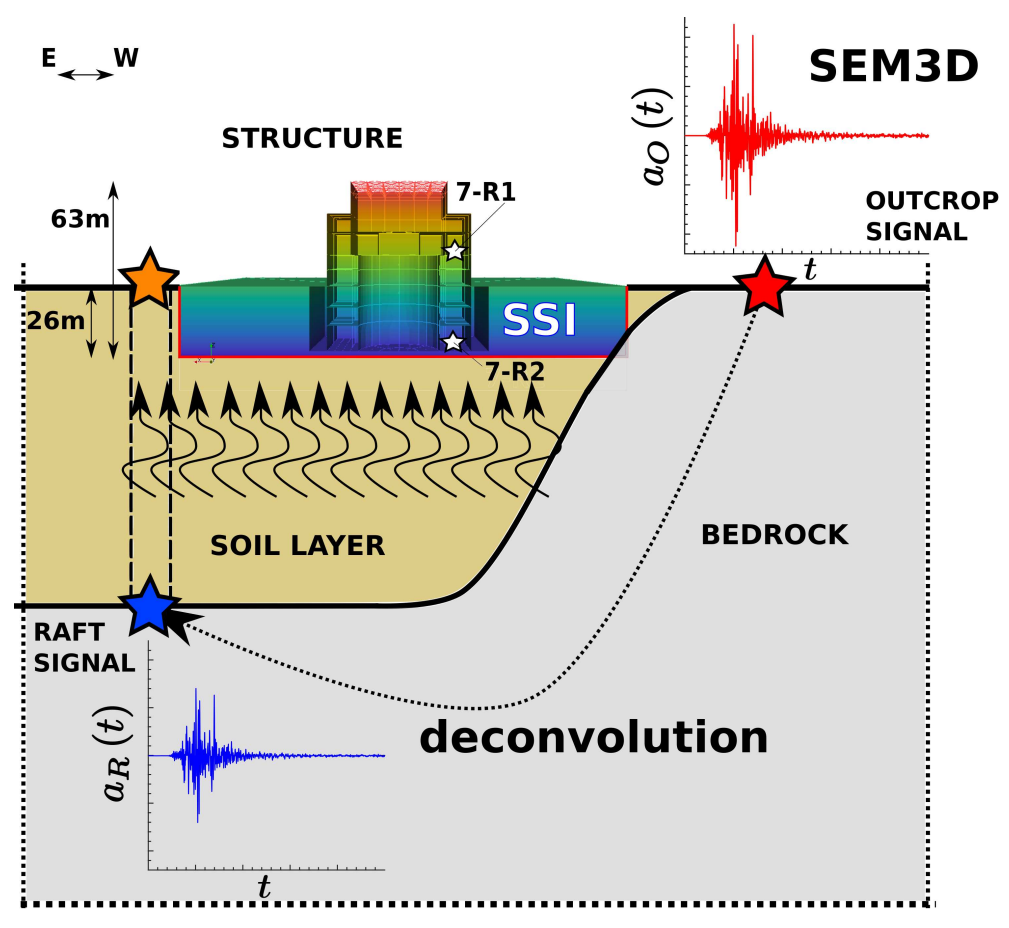

(a)

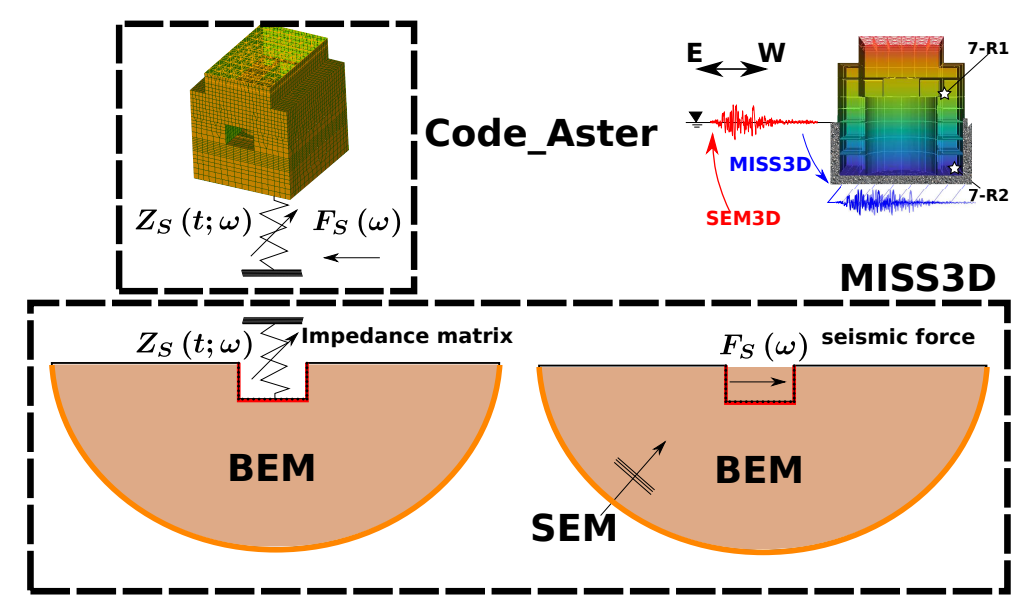

(b)

Figure 5: (a) Conceptual scheme of the SSI problem solved for KKNPP, Unit 7 reactor building (RB7). (b) Scheme of the two-stage coupling adopted in this paper. The synthetic wave-motion (SEM3D) along the soil-structure interface is exploited to excite the FEM model of the reactor building, based on the equivalent seismic forces $F(\omega)$ ( $\omega$ : angular frequency) obtained by convolution between the input motion with the time-frequency impedance matrix function $Z(t ; \omega)$, preliminary determined by BEM (MISS3D). 


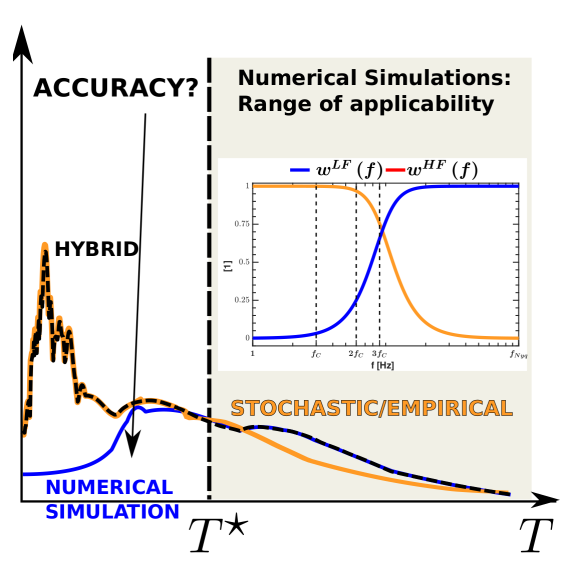

(a)

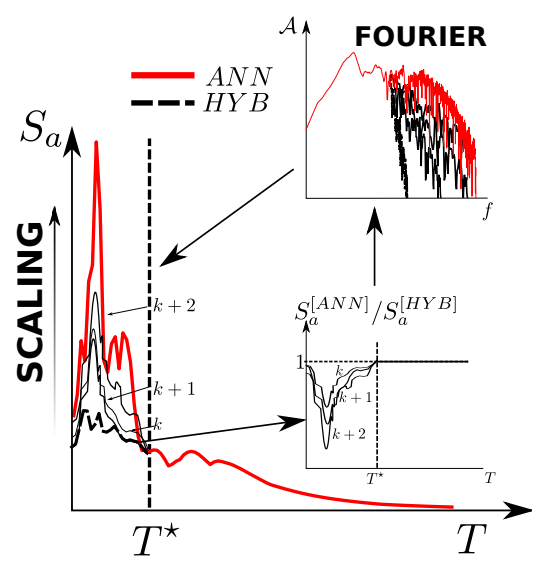

(b)

Figure 6: (a) Sa response spectra obtained by wave-propagation simulation (PBS, blue), by stochastic/empirical predictive methods (STO/EMP, orange) and by classical hybridization methods of the two (HYB, black dashed) (see 13, 41]). (b) Sketch of the Sa spectral matching iterative procedure: the red target spectrum is obtained by ANN prediction upon PBS LP values at long periods. The SP part is iteratively scaled, starting from the HYB trial, by computing the ratio $S a^{(A N N)} / S a^{(H Y B)}$ at each iteration and applying it as a corrective scaling factor in the Fourier's domain.

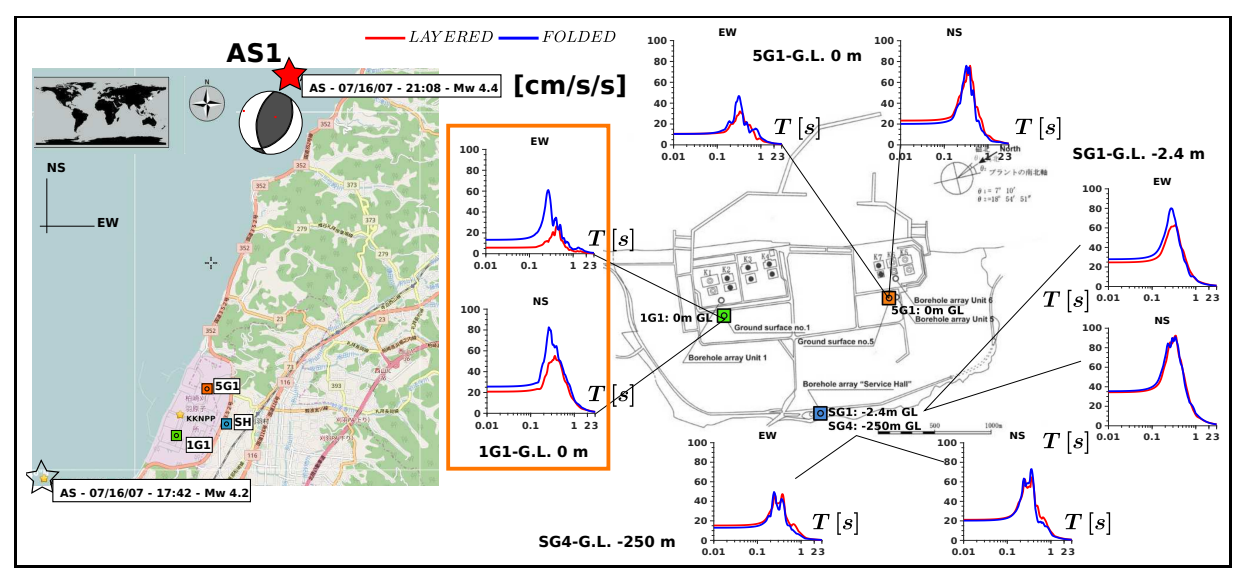

Figure 7: AS1: response spectra $\left(S a\right.$, in $\left.\mathrm{cm} / \mathrm{s}^{2}\right)$ at different locations around the KKNPP site. LAYERED (red) and FOLDED geological models were compared. 


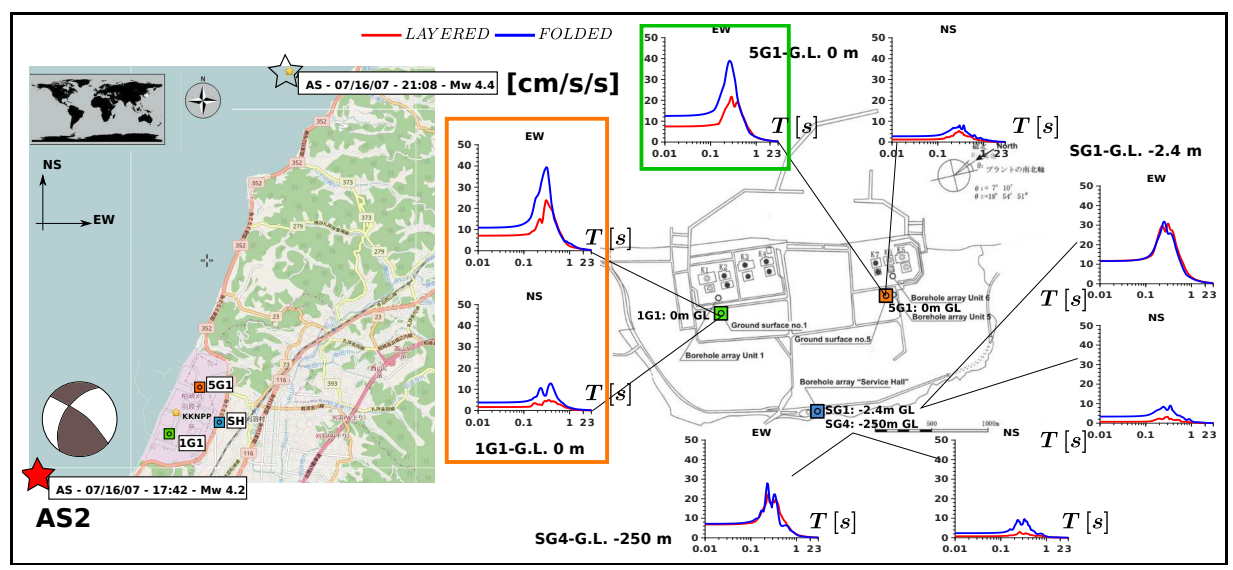

Figure 8: AS2: response spectra $\left(S a\right.$, in $\left.\mathrm{cm} / \mathrm{s}^{2}\right)$ at different location around the KKNPP site. $L A Y E R E D$ (red) and FOLDED geological models were compared.

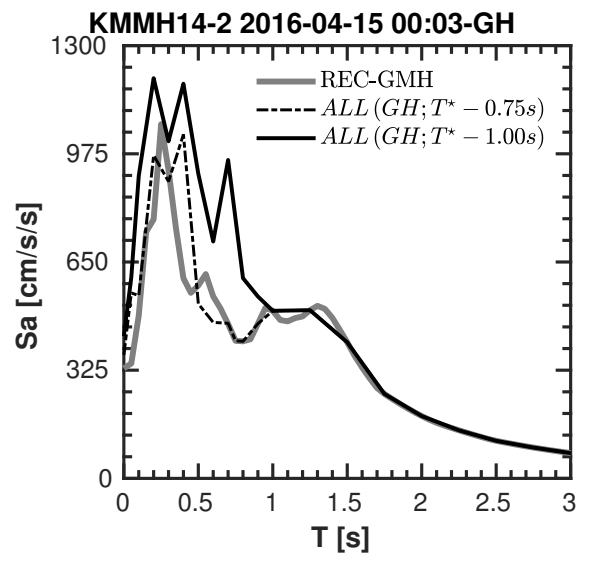

(a)

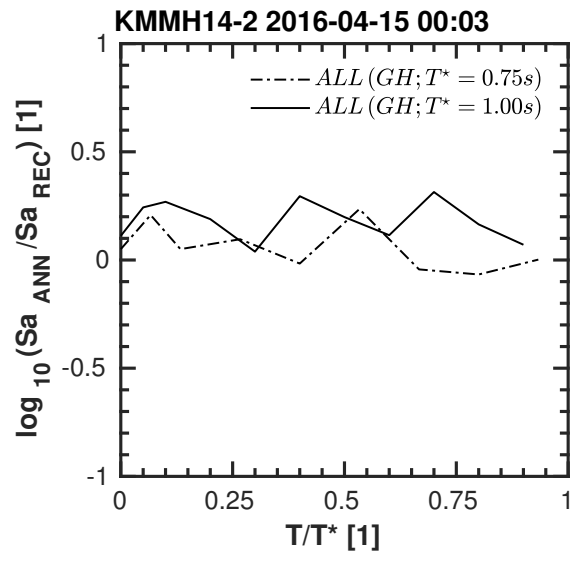

(b)

Figure 9: (a) Recorded (thick gray line) and estimated $S a$ spectra (geometric mean of the horizontal components), for $T^{\star}=0.75 \mathrm{~s}$ (dashed black line) and $T^{\star}=1 \mathrm{~s}$ (solid black line). (b) ANN performance for different training corner periods $T^{\star}$ ( 0.75 and $1 \mathrm{~s}$ respectively), expressed in terms of estimated/target $\mathrm{Sa}$. The data refer to station KMMH14, which recorded the KMM2016 


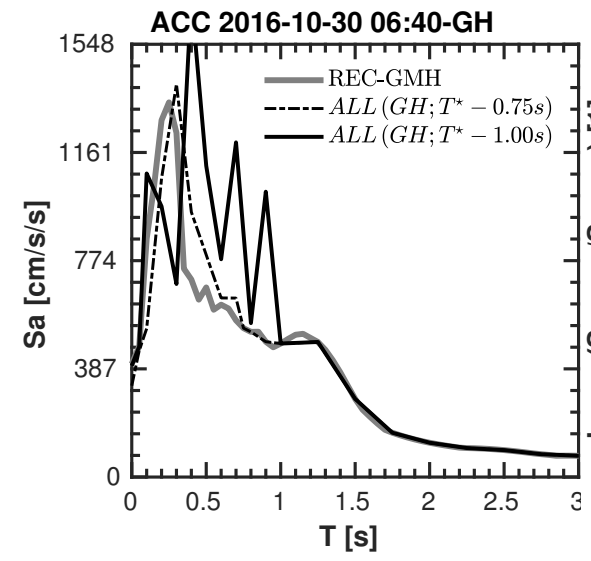

(a)

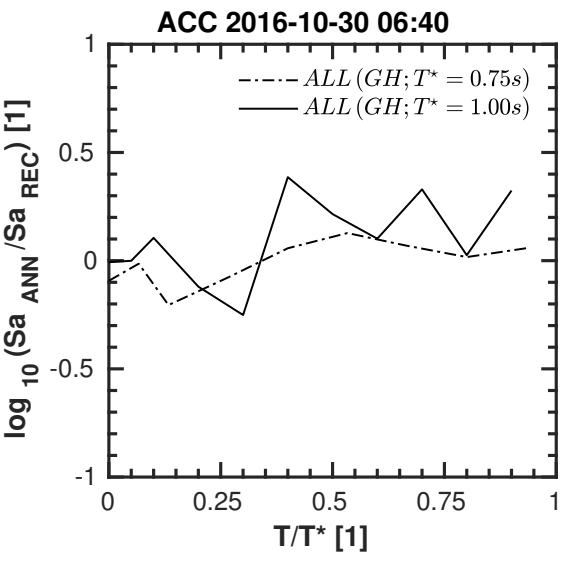

(b)

Figure 10: (a) Recorded (thick gray line) and estimated $S a$ spectra (geometric mean of the horizontal components), for $T^{\star}=0.75 \mathrm{~s}$ (dashed black line) and $T^{\star}=1 \mathrm{~s}$ (solid black line). (b) ANN performance for different training corner periods $T^{\star}(0.75$ and $1 \mathrm{~s}$ respectively), expressed in terms of estimated/target $\mathrm{Sa}$. The data refer to stations ACC, which recorded the CIT2016 


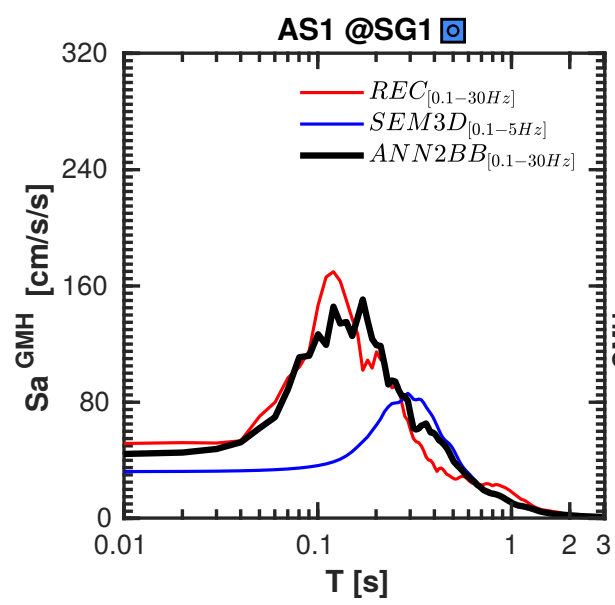

(a)

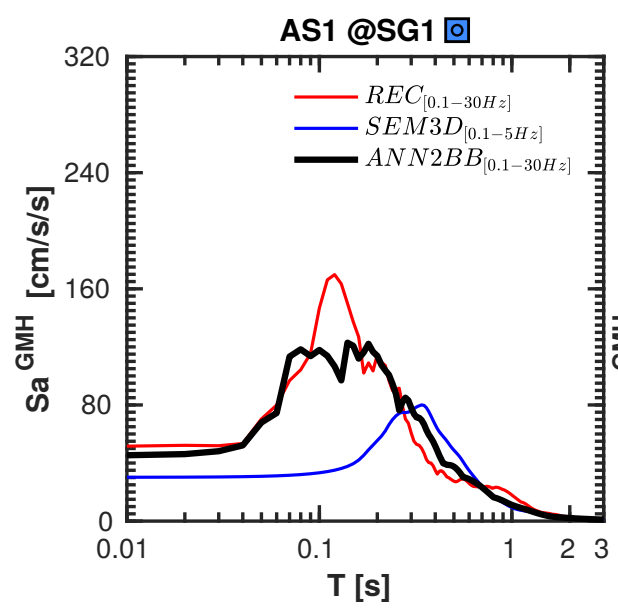

(c)

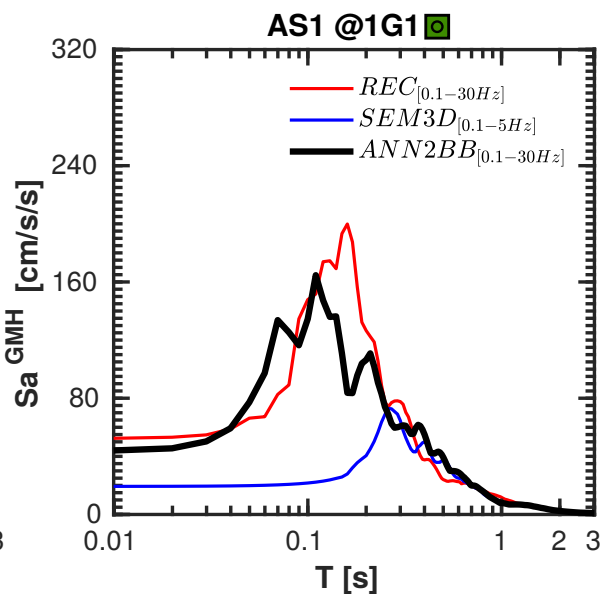

(b)

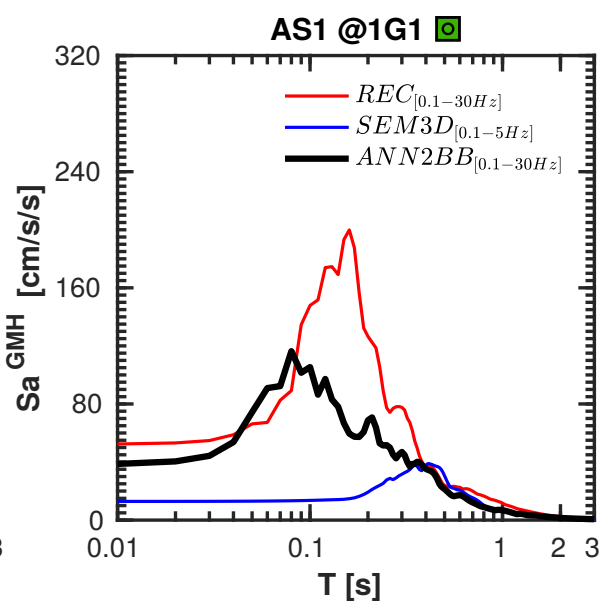

(d)

Figure 11: Pseudo-spectral acceleration response $\left(S a\right.$, in $\left.\mathrm{cm} / \mathrm{s}^{2}\right)$ after ANN2BB application on the SEM3D analysis performed for AS1, at the Service Hall of the KKNPP site: (a-c) SG1, G.L. -250 m, (b-d) 1G1, G.L. 0 m respectively. REC (red), SEM3D (blue) and ANN2BB (black) are the recorded, simulated and enriched $S a$ spectra respectively. Synthetics labelled as REC and ANN2BB were filtered between 0.1-30 Hz, whereas SEM3D synthetics between 0.1-5 Hz. 


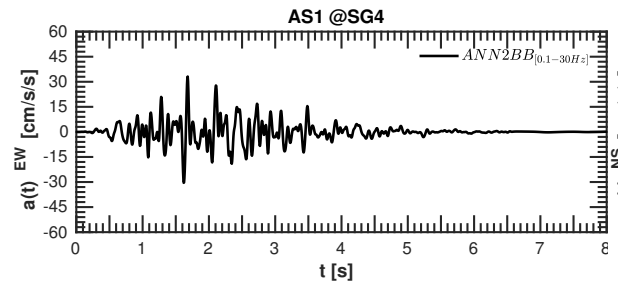

(a)

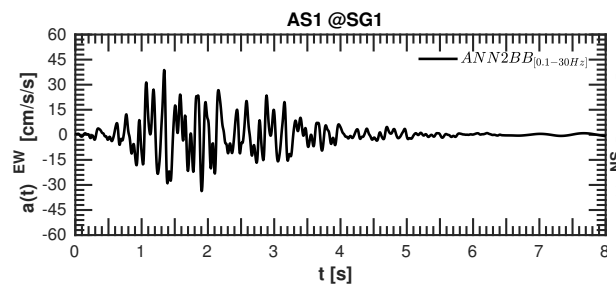

(c)

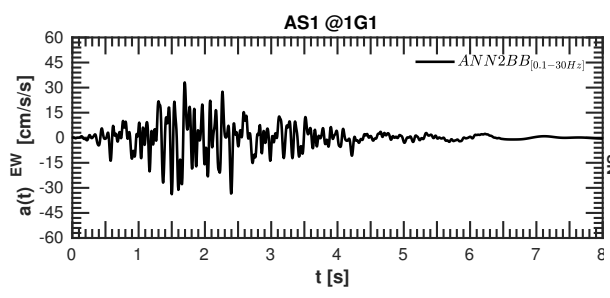

(e)

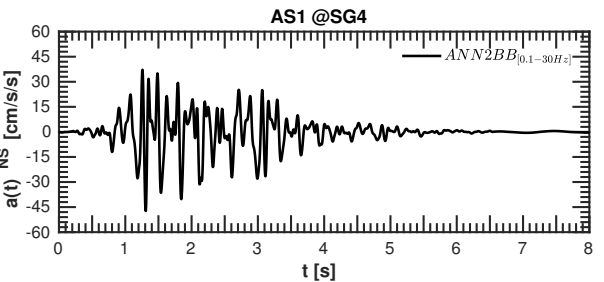

(b)

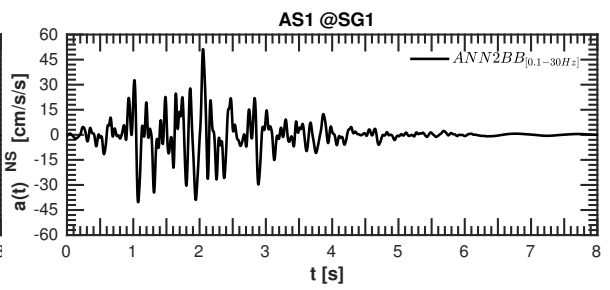

(d)

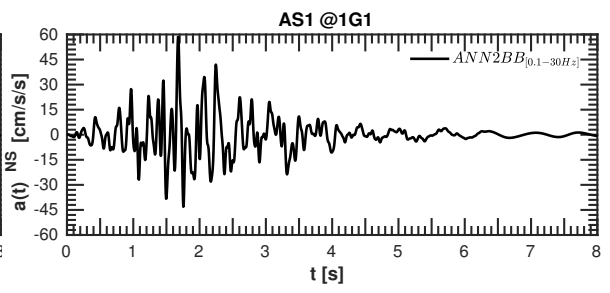

(f)

Figure 12: Acceleration time histories (EW-NS directions, in $\mathrm{cm} / \mathrm{s}^{2}$ ) after ANN2BB application on the SEM3D analysis performed for AS1, at the Service Hall of the KKNPP site: (a-b) SG4, Service Hall, G.L. -250 m; (c-d) SG1, Service Hall, G.L. 0 m; (e-f) 1G1, Unit 1, G.L. 0 m. Synthetics were filtered between $0.1-30 \mathrm{~Hz}$. 


\section{Structural response of a reactor building at KKNPP}

\subsection{Model set-up}

The synthetic wave-motion simulated for aftershock AS1 by SEM3D and enriched by ANN2BB was exploited as input motion for a SSI numerical model (Finite Element Method - Boundary Element Method, FEM-BEM) of the standard reactor building at KKNPP. The structural model consists (as explained in [22]) of a basemat, exterior, interior and auxiliary walls, the Reinforced Concrete Containment Vessel (RCCV), 8 main floors (composed of mainly reinforced concrete slabs and beams, locally few steel beams at same elevations), intermediate reinforced concrete (RC) columns and the steel roof structure. The FEM model (see Figure (13) is featured by 12600 nodes, with Love-Kirchoff plate elements for walls, floors, RCCV and basemat, along with 9700 quadrangular, 2600 triangular and 3300 edge elements. RC beams and columns are modelled as Euler beam whereas Timoshenko beams are used for stick model of reinforced steel bars. Rigid slab conditions were assumed. The main features of the modal analyses performed on the numerical model are reported in Appendix E.2. In this con-

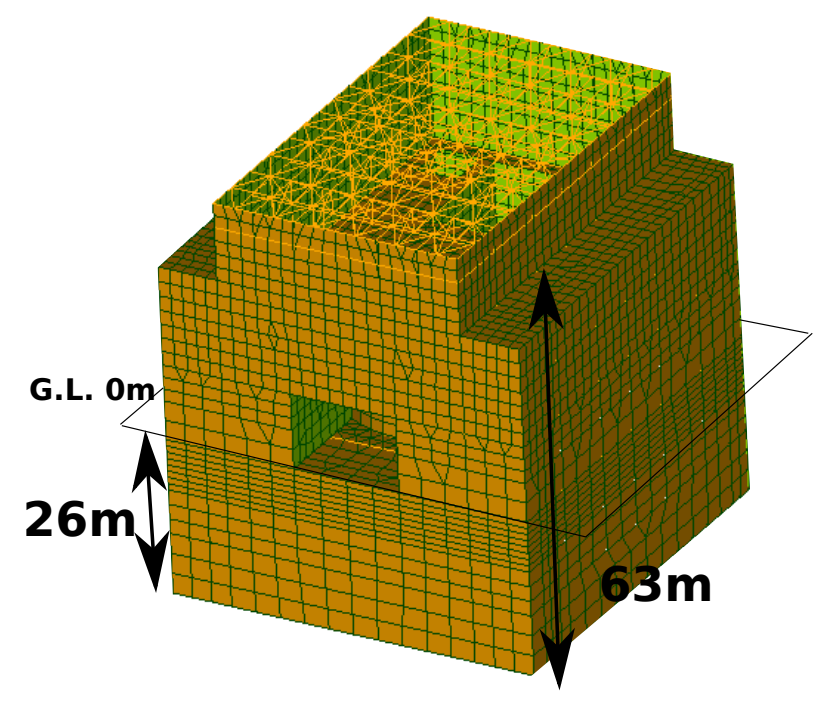

Figure 13: Sketch of the 3-D FEM model (code_aster) of the Reactor Building of KKNPP Unit 7 (RB7). 
text, a feed-forward weak coupling scheme has been conceived (see Figure 5b).

${ }_{425}$ This approach bares upon the domain sub-structuring technique. The computations are carried out by means of coupling between SEM3D+ANN2BB (representing the synthetic broad-band incident wave-field) with MISS3D 5 (BEM), based on the boundary discretization (the soil-structure interface) and it is employed to solve the wave-propagation (in the frequency domain) in a viscoelastic semiinfinite medium (considering the Sommerfeld's conditions) so to compute the impedance matrices and the equivalent seismic forces (in the frequency domain) at the structure basement, and code_aster 6 [36] (FEM) to study the dynamic behaviour of bounded domain (i.e. the reactor building) in time, considering geometrical and material non-linearity [50]. In this case, however, the structural transient wave motion was computed in the elastic framework, with the impedance matrices computed (via BEM) for a sub-horizontally layered configuration of homogeneous/isotropic and linear viscoelastic soil domain (reported in Table E.5) and the SEM synthetic wave-motion was injected (as wave motion on outcrop bedrock, deconvolved at the soil-structure interface) at the soil-structure interface (embedded footing/foundation raft, see Figure 5a). The reactor building (embedded at $-23 \mathrm{~m}$ ) lies on the bedrock layer with $V_{S}=490$ $\mathrm{m} / \mathrm{s}$.

\subsection{Seismic response of the $K K$ reactor building}

Figures 14at 14b show the structural response obtained by prescribing the outcropping broad-band synthetic wave motion obtained with SEM3D (for AS1 and AS2 respectively) and enriched by ANN2BB into the coupled BEM-FEM numerical model of the KKNPP Unit 7 reactor building (RB7). The structural response is presented in terms of Pseudo-Acceleration spectral response $S a(5 \%$

\footnotetext{
${ }^{5}$ Boundary Element Method (BEM) developed at CentraleSupélec (former École Centrale Paris)

${ }^{6}$ Open source Finite Element Method (FEM) software, developed at Électricité de France (EDF) - https://www .code-aster.org/V2/spip.php?rubrique2
} 


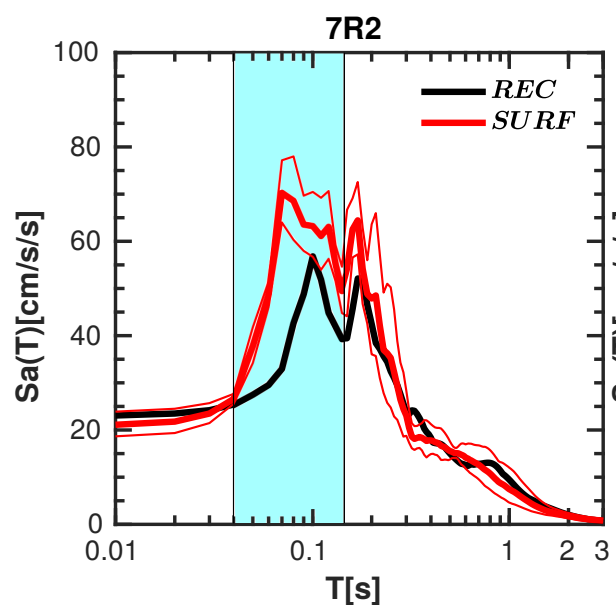

(a)

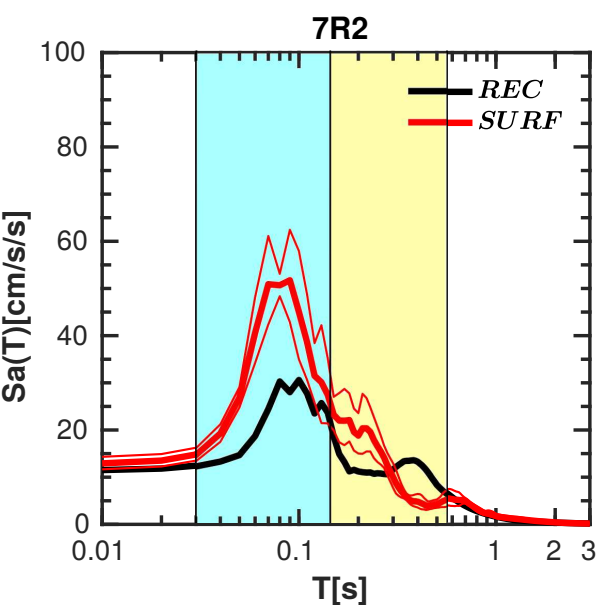

(b)

Figure 14: Recorded (black) Sa spectrum (5\% damping) at the basement mat the reactor building (7R2), compared to the synthetic counterpart, obtained by inputting the simulated ground motion at SG1 (surface free-field wave motion, referring at the KKNPP Service Hall). (a) Aftershock AS1; (b) aftershock AS2. Records and synthetics were both filtered between 0-30 Hz. The $S a$ response spectra were computed on rotated components of the original EW-NS directions, in a $\left[0-180^{\circ}\right]$ range, with a $10^{\circ}$ increment. Thick lines refer to the logaverage of the geometric mean on the two horizontal directions, whereas thin lines refer to the log-average \pm standard deviation.

damping) at the reactor building basement and at a recording point located at the foundation level (7R2). For the two aftershocks AS1 and AS2, no recordings at other control points on the reactor building are available. Although synthetic and recorded $S a$ spectra show some discrepancies, the simulation satisfactorily mimics the spectral shapes, for both AS1 (showing a double peak) and AS2 (mono-peaked). Especially, a fairly good match is showcased in terms of PGA values. SEM3D simulations for AS1 are better matching the recordings at long periods, whereas a certain discrepancy appears for AS2, due to the details of the physics-based model and the geological features considered (see shaded area in Figure 14b). The encountered deviance for $T<0.2 \mathrm{~s}$ (shaded areas) must probably be due to the simplified assumptions adopted to solve the linear SSI problem, 

the seismic robustness of critical structures. The presented case-study proves that the modeling strategy adopted is adapted for the structural design of critical structures, such as nuclear power plants, as well as the verification of the seismic response of the existing ones. However, it is strongly dependent on the fluence of complex ruptures paths on extended fault planes undoubtedly plays a crucial role on the wave field the structure is subjected to. This entails the 
need to extend the present study to the uncertainty quantification of the source mechanisms. To this end, the scientific work-flow outlined herein is prone to perform this task.

Considering the simulation of the structural response, a weak coupling solution was adopted, accounting for the standard engineering practice. Although neglected, the non-linear SSI can be integrated into the described work-flow

by domain-reduction method [2], or by strong coupling schemes [52], either by refined strategies to compute time-convolution integrals arising on the interface when one (linear) subdomain is modelled by an impedance operator and the other exhibits non-linear behaviour [50]. However, from a structural design perspective (hazard and vulnerability), the modeling strategy fosters the investigation of seismic contexts characterized by poor observational databases, such as the low seismicity of metropolitan France, where numerous nuclear installations are present. Further investigations are however necessary, which will likely be performed by verification and validation benchmarks, so to outline in details the improvements and the practical performances of the proposed strategy compared to others, as well as possible shortcomings [53]. In the nuclear engineering and industrial contexts, this task is mandatory for a rigorous quality control of the complex tool-chain adopted for the design and vulnerability assessment of such critical structures.

\section{Data and Resources}

The authors are very grateful to the Tokyo Electric Power Company (TEPCO) for providing such high-quality earthquake recordings of the Niigata-Ken ChüetsuOki, reported in [18].

Time histories and velocity profiles used in this study were collected from the KiK-net website: http://www.kik.bosai.go.jp/kik/ (last accessed November 2011). The authors are very grateful to the National Research Institute for Earth Science and Disaster Prevention (NIED) for providing such high-quality 
earthquake recordings.

520

Research Institute for Earth Science and Disaster Resilience (NIED DMC), which provides continuous seismic waveform and other seismological data obtained by the NIED High Sensitivity Seismograph Network (NIED Hi-net) and the other seismograph networks in Japan. NIED, Japan Meteorological Agency data obtained by each seismic network with a specific policy for Exchange and Open Access of Waveform Data obtained by High Sensitivity Seismograph Observation conducted by the Headquarters for Earthquake Research Promotion of the Japanese government. The website (http://www.hinet.bosai.go.jp/?LANG=en) sensitivity seismograph data.

The Digital Elevation Model belongs to the Shuttle Radar Topography Mission (SRTM) database, result from a collaborative effort by the National Aeronau535 tics and Space Administration (NASA) and the National Geospatial-Intelligence Agency (NGA), as well as the participation of the German and Italian space agencies, to generate a near-global digital elevation model (DEM) of the Earth using radar interferometry. Source: https://dds.cr.usgs.gov/srtm/version2_1 (last accessed January 2009).

\section{Acknowledgments}

This work, within the SINAPS@ project, benefited from French state funding managed by the National Research Agency under program RNSR Future Investments bearing reference No. ANR-11-RSNR-0022-04. The research reported in this paper has been supported in part by the SEISM Paris Saclay ${ }_{545}$ Research Institute. 


\section{References}

[1] A. Lavell, Programme for Risk Management in Central America: Ideas and notions relating to concept and practices, in: United Nations Development Programme (UNDP), 2003.

[2] J. Bielak, K. Loukakis, Y. Hisada, C. Yoshimura, Y. Chiaki, A. Ferna, J. Bielak, Y. Hisada, A. Ferna, Domain Reduction Method for ThreeDimensional Earthquake Modeling in Localized Regions. Part 1: Theory, Bulletin of the Seismological Society of America 93 (2) (2003) 817-840.

[3] J. A. Abell, N. Orbović, D. B. McCallen, B. Jeremić, Earthquake soil-structure interaction of nuclear power plants, differences in response to $3-\mathrm{D}$, 3 x1-D, and 1-D excitations, Earthquake Engineering and Structural Dynamicsdoi:10.1002/eqe.3026.

URL http:https://doi.org/10.1002/eqe.3026

[4] T. Ichimura, M. Hori, Strong ground motion prediction using macro-micro analysis method, Earthquake Engineering \& Structural Dynamics 35 (4) (2006) 395-417. doi:10.1002/eqe.532.

URL http:https://doi.org/10.1002/eqe.532

[5] T. Ichimura, M. Hori, Macro-micro analysis method for wave propagation in stochastic media, Earthquake Engineering \& Structural Dynamics 35 (4) (2006) 419-432. doi:10.1002/eqe.533.

URL http:https://doi.org/10.1002/eqe.533

[6] P. E. B. Quinay, T. Ichimura, M. Hori, A. Nishida, S. Yoshimura, Seismic Structural Response Estimates of a Fault-Structure System Model with Fine Resolution Using Multiscale Analysis with Parallel Simulation of Seismic-Wave Propagation, Bulletin of the Seismological Society of America 103 (3) (2013) 2094-2110.

[7] H. Fu, C. He, B. Chen, Z. Yin, Z. Zhang, W. Zhang, T. Zhang, W. Xue, W. Liu, W. Yin, G. Yang, X. Chen, 18.9Pflopss Nonlinear Earthquake Sim- 


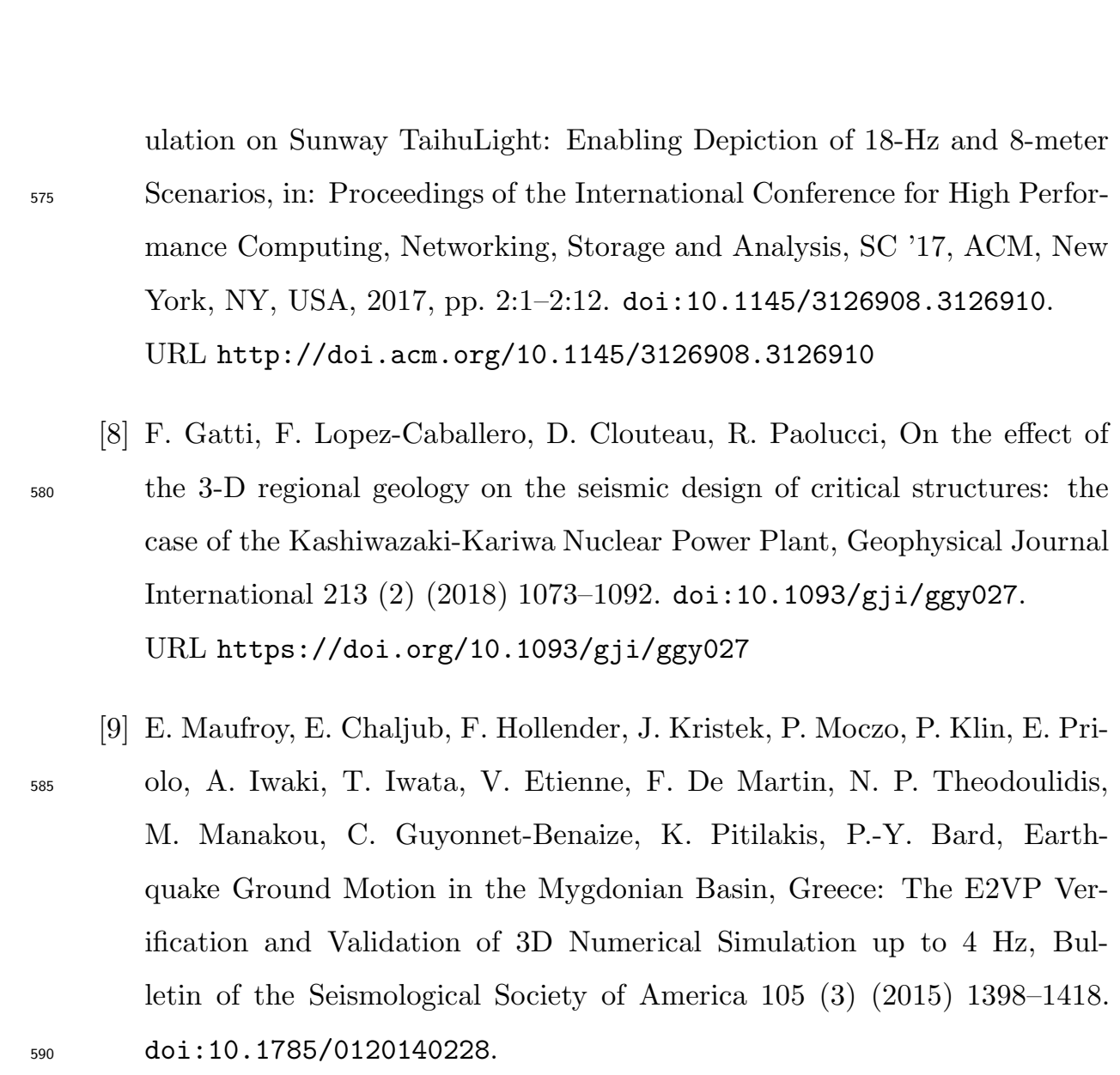

[10] B. T. Aagaard, R. W. Graves, A. Rodgers, T. M. Brocher, R. W. Simpson, D. Dreger, N. A. Petersson, S. C. Larsen, S. Ma, R. C. Jachens, Ground-Motion Modeling of Hayward Fault Scenario Earthquakes, Part II: Simulation of Long-Period and Broadband Ground Motions, Bul$595 \quad$ letin of the Seismological Society of America 100 (6) (2010) 2945-2977. arXiv:http://www.bssaonline.org/content/100/6/2945.full.pdf+html, doi:10.1785/0120090379.

URL http: //www . bssaonline.org/content/100/6/2945. abstract

[11] C. A. Goulet, N. A. Abrahamson, P. G. Somerville, K. E. 600 Wooddell, The SCEC Broadband Platform Validation Exercise: Methodology for Code Validation in the Context of Seismic-Hazard Analyses, Seismological Research Letters 86 (1) (2014) 17. 
arXiv:/gsw/content_public/journal/srl/86/1/10.1785_0220140104/4/17.pdf, doi:10.1785/0220140104.

[12] M. Vazquez, G. Houzeaux, S. Koric, A. Artigues, J. Aguado-Sierra, R. Aris, D. Mira, H. Calmet, F. Cucchietti, H. Owen, A. Taha, J. M. Cela, Alya: Towards Exascale for Engineering Simulation Codes, Physics.

URL http://arxiv.org/abs/1404.4881v1

[13] R. W. Graves, A. Pitarka, Broadband time history simulation using a hybrid approach, in: $13^{\text {th }}$ World Conference on Earthquake Engineering, Vancouver, B.C., Canada, 2004.

[14] C. Berge-Thierry, A. Svay, A. Laurendeau, T. Chartier, V. Perron, C. Guyonnet-Benaize, E. Kishta, R. Cottereau, F. Lopez-Caballero, F. Hollender, B. Richard, F. Ragueneau, F. Voldoire, F. Banci, I. Zentner, N. Moussallam, M. Lancieri, P.-Y. Bard, S. Grange, S. Erlicher, P. Kotronis, A. L. Maoult, M. Nicolas, J. Rgnier, F. Bonilla, N. Theodoulidis, Toward an integrated seismic risk assessment for nuclear safety improving current French methodologies through the SINAPS@ research project, Nuclear Engineering and Design 323 (Supplement C) (2017) 185 - 201. doi:https://doi.org/10.1016/j.nucengdes.2016.07.004. URL http://www.sciencedirect.com/science/article/pii/S0029549316302072

[15] F. Gatti, Forward physics-based analysis of "source-to-site" seismic scenarios for strong ground motion prediction and seismic vulnerability assessment of critical structures, Theses, Université Paris-Saclay - CentraleSupélec and Politecnico di Milano (Sep. 2017).

URL https://tel.archives-ouvertes.fr/tel-01626230

[16] B. A. Bradley, D. Pettinga, J. W. Baker, J. Fraser, Guidance on the Utilization of Earthquake-Induced Ground Motion Simulations in Engineering Practice, Earthquake Spectradoi:10.1193/120216EQS219EP 
[17] Y. Shiba, Source process and broadband strong motions during the Niigata-ken Chuetsu-Oki earthquake in 2007, Denryoku Chuo Kenkyusho Hokoku (N08007) (2008) 1-4, japanese with English Abstract.

URL https://inis . iaea.org/search/searchsinglerecord. aspx?recordsFor=SingleRecord\&RN=401

[18] TEPCO, The data analysis recorded at the Kashiwazaki Kariwa Nuclear Power Plant during the 2007 Niigata-ken Chuetsu-oki earthquake, Tech. rep., The Tokyo Electric Power Company, Inc, in Japanese (2007). URL http://www.tepco.co.jp/cc/press/betu07_j/images/070730d.pdf

[19] T. Watanabe, T. Moroi, M. Nagano, R. Tokumitsu, M. Kikuchi, I. Nishimura, Analysis of the strong motion records obtained from the 2007 Niigataken Chuetsu-Oki earthquake and determination of the design basis ground motions at the Kashiwazaki Kariwa Nuclear Power Plant. Part 2. Difference of site amplification based on the 2D FEM analysis of the folded structure, Tech. rep. (2009).

[20] K. Tsuda, T. Hayakawa, T. Uetake, K. Hikima, R. Tokimitsu, H. Nagumo, Y. Shiba, Modeling 3D Velocity Structure in the Fault Region of the 2007 Niigataken Chuetu-Oki Earthquake with Folding Structure, in: $4^{\text {th }}$ IASPEI/IAEE International Symposium-Effects of Surface Geology on Seismic Motion, 2011, pp. 1-11.

[21] R. Paolucci, F. Gatti, M. Infantino, A. G. Ozcebe, C. Smerzini, M. Stupazzini, Broad-band ground motions from 3D physics-based numerical simulations using Artificial Neural Networks, Bulletin of the Seismological Society of America Pre-Issue Publication (BSSA-D-17-00293R2). doi:https://doi.org/10.1785/0120170293

[22] F. Turpin, L. Bonfils, N. Suin, N. Humbert, I. Petre-Lazar, Seismic analysis with Soil-Structure Interaction KARISMA benchmark Benchmark, in: 15th World Conference on Earthquake Engineering, 2012.

[23] IAEA, Review of Seismic Evaluation Methodologies for Nuclear Power Plants Based on a Benchmark Exercise, TECDOC 1722, International 
Atomic Energy Agency, Wien, iAEA-TECDOC-1722 (2013).

URL http://www-pub.iaea.org/books/IAEABooks/10580/Review-of-Seismic-Evaluation-Methodo-

[24] O. V. Pavlenko, K. Irikura, Nonlinear Soil Behavior at the KashiwazakiKariwa Nuclear Power Plant During the Niigata Chuetsu-Oki Earthquake (July, 16, 2007), Pure and Applied Geophysics 169 (10) (2012) 1777-1800. doi:10.1007/s00024-011-0447-3.

[25] F. Gatti, F. Lopez-Caballero, R. Paolucci, D. Clouteau, Near-source effects and non-linear site response at Kashi wazaki-Kariwa Nuclear Power Plant, in the 2007 Chuetsu-Oki earthquake: evidence from surface and downhole records and 1D numerical simulations, Bulletin of Earthquake Engineering 16 (3) (2017) 1105-1135. doi:10.1007/s10518-017-0255-y. URL https://doi.org/10.1007/s10518-017-0255-y

[26] V. A. Fernandes, F. Banci, G. Devesa, N. Greffet, M. Jacquet, M. Kham, A. Nieto-Ferro, F. Voldoire, I. Zentner, DYNAMIC SOILSTRUCTURE INTERACTION MODELING STRATEGIES APPLIED TO KASHIWAZAKI-KARIWA NUCLEAR POWER PLANT CASESTUDY, in: M. F. M. Papadrakakis (Ed.), Eccomas Proceedia COMPDYN, 6th ECCOMAS Thematic Conference on Computational Methods in Structural Dynamics and Earthquake Engineering, 2017, pp. 2381-2394. doi:10.7712/120117.5571.17197.

[27] H. Aochi, A. Ducellier, F. Dupros, M. Delatre, T. Ulrich, F. de Martin, M. Yoshimi, Finite difference simulations of seismic wave propagation for the $2007 \mathrm{Mw}$ 6.6 Niigata-ken Chuetsu-Oki earthquake: Validity of models and reliable input ground motion in the near field, Pure and Applied Geophysics 170 ((1-2)) (2013) 43-64, springer Verlag (Germany). doi:10.1007/s00024-011-0429-5. URL https://hal-brgm.archives-ouvertes.fr/hal-00980238

[28] T. Watanabe, T. Moroi, R. Tokumitsu, I. Nishimura, K. Hijikata, Examination of relation between locations of asperities and site amplifica- 
tion characteristics of ground motions by analysis considering the folded structure-Estimation based on the strong motion records obtained from the 2007 Niigataken Chuetsu-oki earthquake in the Kashiwazaki-Kariwa Nuclear Power Station, Journal of Structural and Construction Engineering 76 (659) (2011) 71-78.

[29] A. Patera, A spectral element method for fluid dynamics: Laminar flow in a channel expansion, Journal of Computational Physics 54 (3) (1984) 468 - 488. doi:http://dx.doi.org/10.1016/0021-9991(84)90128-1 URL http://www.sciencedirect.com/science/article/pii/0021999184901281

[30] E. Faccioli, F. Maggio, R. Paolucci, A. Quarteroni, 2D and 3D elastic wave propagation by a pseudo-spectral domain decomposition method, Journal of Seismology 1 (3) (1997) 237-251. doi:10.1023/A:1009758820546.

[31] P. Cupillard, E. Delavaud, G. Burgos, G. Festa, J.-P. Vilotte, Y. Capdeville, J.-P. Montagner, RegSEM: a versatile code based on the spectral element method to compute seismic wave propagation at the regional scale, Geophysical Journal International 188 (3) (2012) 1203-1220.

[32] G. Festa, J.-P. Vilotte, The Newmark scheme as velocity-stress time-staggering: an efficient PML implementation for spectral element simulations of elastodynamics, Geophysical Journal International 161 (3) (2005) 789-812. doi:10.1111/j.1365-246X.2005.02601.x URL http://www . scopus . com/inward/record.url?eid=2-s2.0-20444501406\{\&\}partnerID=tZOtx3y1

[33] G. Seriani, E. Priolo, Spectral element method for acoustic wave simulation in heterogeneous media, Finite Elements in Analysis and Design 16 (3) (1994) 337 - 348, special Issue Selection of Papers Presented at ICOSAHOM'92. doi:https://doi.org/10.1016/0168-874X(94)90076-0. URL http://www.sciencedirect.com/science/article/pii/0168874X94900760

715 [34] F. Gatti, L. D. C. Paludo, A. Svay, F. Lopez-Caballero, R. Cottereau, D. Clouteau, Investigation of the earthquake ground mo- 


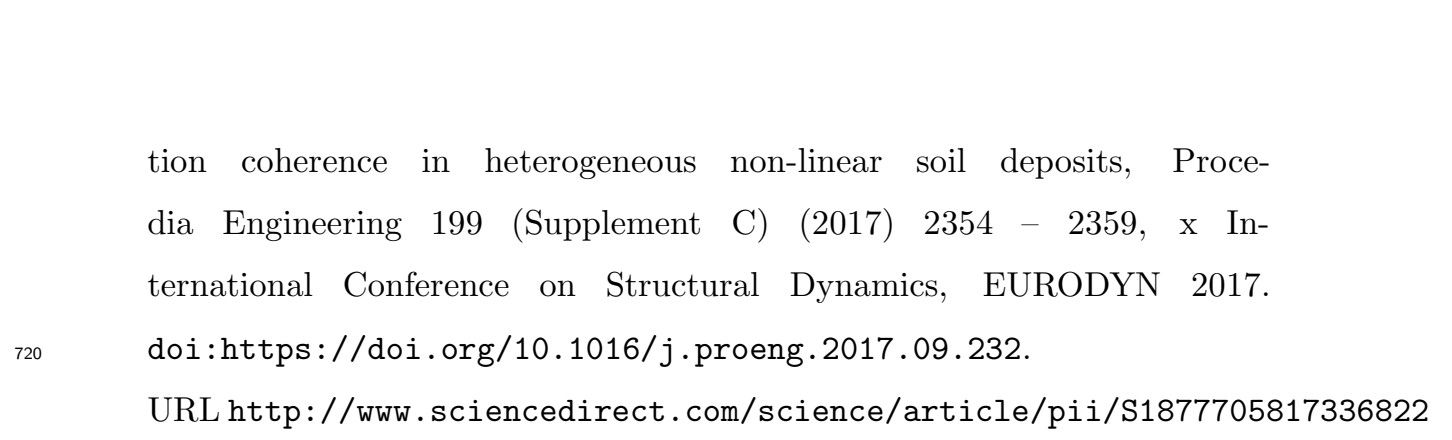

[35] L. de Abreu Corrêa, J. J. Camata, L. de Carvalho Paludo, L. Aubry, R. Cottereau, A. L. G. A. Coutinho, Wave propagation in highly heterogeneous media: scalability of the mesh and random properties generator, Submitted for publication in Computers \& Geosciences.

[36] code_aster, General public licensed structural mechanics finite element software, included in the Salomé-Méca simulation platform., Tech. rep., Électricité de France (EDF) (2001).

URL http://www . code-aster.org

[37] S. Touhami, V. A. Fernandes, F. Lopez-Caballero, STRUCTURE-SOILSTRUCTURE INTERACTION ANALYSIS OF NUPEC TEST CASES, in: M. F. M. Papadrakakis (Ed.), Eccomas Proceedia COMPDYN, 6th ECCOMAS Thematic Conference on Computational Methods in Structural Dynamics and Earthquake Engineering, 2017.

[38] G. Devesa, V. Guyonvarh, D. Clouteau, Use of coupled and regulatory method in Soil-Structure Interaction and Soil-Fluid-Structure Interaction for nuclear plants and dams, in: First European Conference on Earthquake Engineering and Seismology, Geneva, 2006.

[39] D. Clouteau, D. Broc, G. Devésa, V. Guyonvarh, P. Massin, Calculation methods of Structure-Soil-Structure Interaction (3SI) for embedded buildings: Application to NUPEC tests, Soil Dynamics and Earthquake Engineering 32 (1) (2012) 129 - 142. doi:https://doi.org/10.1016/j.soildyn.2011.08.005 URL http://www.sciencedirect.com/science/article/pii/S0267726111002375 
[45] C. Smerzini, C. Galasso, I. Iervolino, R. Paolucci, Ground motion record selection based on broadband spectral compatibility, Earthquake Spectra 30 (4) (2014) 1427-1448.

[46] C. Bishop, Neural Networks for Pattern Recognition, Clarendon Press 770

[47] C. Bishop, C. Roach, Fast Curve Fitting using Neural Networks, Review of Scientific Instruments 63 (10). 
[48] K. Levenberg, A method for the solution of certain non-linear problems in least squares, Quarterly of applied mathematics 2 (2) (1944) 164-168.

[49] D. W. Marquardt, An algorithm for least-squares estimation of nonlinear parameters, Journal of the society for Industrial and Applied Mathematics 11 (2) (1963) 431-441.

[50] A. N. Ferro, D. Clouteau, N. Greffet, G. Devésa, On a hybrid Laplace-time domain approach to dynamic interaction problems, European Journal of Computational Mechanics 21 (3-6) (2012) 290-299. arXiv:https://www.tandfonline.com/doi/pdf/10.1080/17797179.2012.731254, doi:10.1080/17797179.2012.731254. URL https://www.tandfonline.com/doi/abs/10.1080/17797179.2012.731254

[51] A. Svay, Modelling of Spatial Variability of Seismic Ground Motions for Soil-Structure Interaction Analysis, Theses, Université Paris-Saclay (Feb. 2017).

URL https://tel.archives-ouvertes.fr/tel-01544447

[52] T. M. Schlittler, R. Cottereau, Fully scalable implementation of a volume coupling scheme for the modeling of multiscale materials, Computational Mechanics 60 (5) (2017) 827-844. doi:10.1007/s00466-017-1445-9. URL https://doi.org/10.1007/s00466-017-1445-9

[53] I. Babuska, J. T. Oden, Verification and validation in computational engineering and science: basic concepts, Computer methods in applied mechanics and engineering 193 (36-38) (2004) 4057-4066.

795 [54] I. Mazzieri, M. Stupazzini, R. Guidotti, C. Smerzini, SPEED: SPectral Elements in Elastodynamics with Discontinuous Galerkin: a non-conforming approach for 3D multi-scale problems, International Journal for Numerical Methods in Engineering 95 (12) (2013) 991-1010.

[55] F. De Martin, Verification of a Spectral-Element Method Code for the Southern California Earthquake Center LOH.3 Viscoelastic Case, Bul- 
letin of the Seismological Society of America 101 (6) (2011) 2855-2865.

arXiv:http://geoscienceworld.org/content/101/6/2855.full.pdf,

doi:10.1785/0120100305.

URL http://geoscienceworld.org/content/101/6/2855

[63] J.-P. Berenger, A perfectly matched layer for the absorption of electromagnetic waves, Journal of computational physics 114 (2) (1994) 185-200. 


\section{Appendix A. Abbreviations}

Table A.4: List of abbreviations used in this paper.

\begin{tabular}{|c|c|}
\hline Abbreviation & Expanded \\
\hline ANN & Artificial Neural Network \\
\hline AS1 & After Shock 1 \\
\hline $\mathrm{AS} 2$ & After Shock 2 \\
\hline $\mathrm{BB}$ & Broad Band \\
\hline BEM & Boundary Element Method \\
\hline CIT2016 & 2016 Central Italy Earthquake \\
\hline DRM & Domain Reduction Method \\
\hline FEM & Finite Element Method \\
\hline G.L. & Ground Level \\
\hline $\mathrm{HF}$ & High Frequency \\
\hline $\mathrm{HPC}$ & High Performance Computing \\
\hline IM & Intensity Measure \\
\hline KKNPP & Kashiwazaki-Kariwa Nuclear Power Plant \\
\hline KMM2016 & 2016 Kumamoto Earthquake \\
\hline $\mathrm{LF}$ & Low Frequency \\
\hline LP & Long Period \\
\hline MMAM & Micro-Macro Analysis Method \\
\hline NCOEQ-2007 & 2007 Niigata-Ken Chūetsu-Oki \\
\hline PGA & Peak Ground Acceleration \\
\hline PGV & Peak Ground Velocity \\
\hline$S a$ & Spectral Acceleration \\
\hline SEM & Spectral Element Method \\
\hline $\mathrm{SP}$ & Short Period \\
\hline SSI & Soil Structure Interaction \\
\hline
\end{tabular}


Appendix B. ANN2BB complementary results 


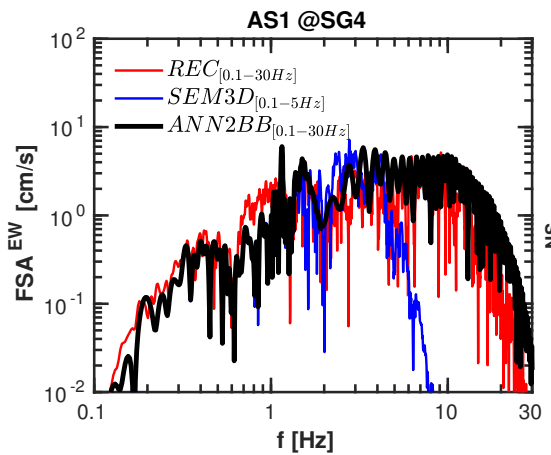

(a)

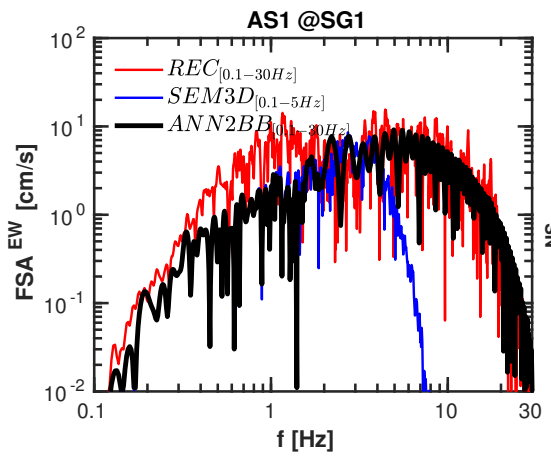

(c)

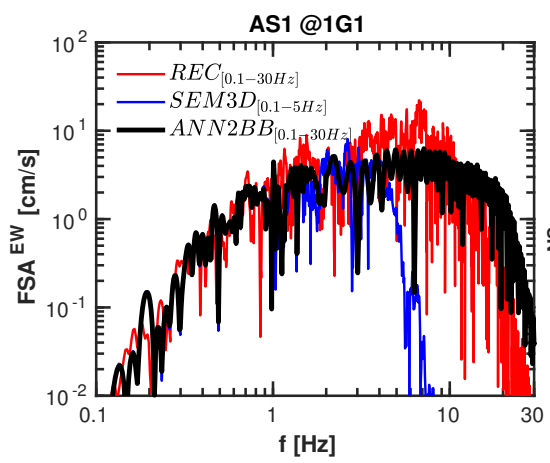

(e)

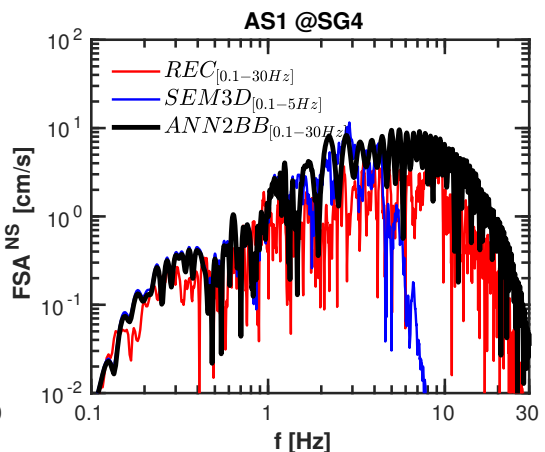

(b)

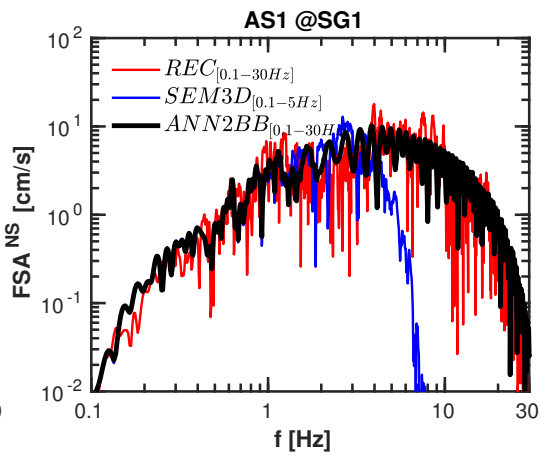

(d)

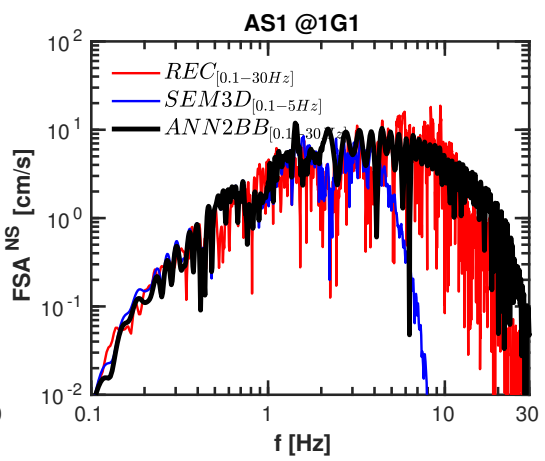

(f)

Figure B.15: Fourier's spectral acceleration (FSA, in cm/s) after ANN2BB application on the SEM3D analysis performed for AS1, at the Service Hall of the KKNPP site: (a-b) SG4, Service Hall, G.L. -250 m; (c-d) SG1, Service Hall, G.L. 0 m; (e-f) 1G1, Unit 1, G.L. 0 m. REC (red), SEM3D (blue) and ANN2BB (black) are the recorded, simulated and enriched FSA respectively. Synthetics labelled as REC and ANN2BB were filtered between 0.1-30 Hz, whereas SEM3D synthetics between 0.1-5 Hz. 


\section{Appendix C. The Spectral Element Method for elastodynamics}

The SEM borrowed from the FEM its natural capability to handle both interface and free boundary surface conditions, allowing a good resolution of evanescent interface and surface waves [31]. As in FEM, the semi-discretized equations are obtained by first rewriting the linear momentum equations in their variational formulation and then by subdividing the spatial domain $\bar{\Omega}$ into $N_{e}$ non-overlapping elements $\bar{\Omega}_{e}$ (generally hexahedral elements) such that $\bar{\Omega}=\cup_{e=1, N_{e}} \bar{\Omega}_{e}$ and the intersection between two distinct elements $e^{\prime}$ and $e$ $\bar{\Omega}_{e^{\prime}} \cap \bar{\Omega}_{e}$ is an element's corner, edge or face. The approximate solution of the Euler-Lagrange problem (i.e. the displacement/velocity couple $\left.\left(\underline{\boldsymbol{u}}^{h} ; \underline{\boldsymbol{v}}^{h}\right)\right)$ is sought in the space of high-order piece-wise polynomial on the element $\Omega_{e}$. Specifically, the SEM employs tensorized (and orthogonal) Lagrangian polynomials of order $N^{d}$ as basis functions (Lagrange polynomial of first or second order for a linear ( 8 nodes) or parabolic (27 nodes) description of the hexahedral element, respectively). The tensorial grid features $(N+1)^{d}$ interpolation nodes of belonging to the Gauss-Lobatto-Legendre (GLL) set. Those GLLs are involved in the Gauss quadrature used to evaluate the integrals in the variational formulation and to discretize the displacement and velocity fields, their derivatives and the external forces. Moreover, the choice of a Lagrangian interpolation associated with the GLL nodes gives the SEM a very interesting convergence property: an increase of the polynomial order leads to an exponential diminution of the aliasing error(the the so called spectral precision [31, 54]). According to previous studies [55], Lagrange polynomials of order 4 and a mean of 5.7 GLL points per minimum S wave-length are sufficient to compute accurate wave-motion. Accurate stability and convergence analyses are provided in [56]. Substituting the piecewise polynomial approximation into the variational counterpart of the Euler-Lagrange equations and approximating the integrals by means of the Gauss quadrature rules (based on the GLL tensorized grid) 7 lead

\footnotetext{
${ }^{7}$ The complete mathematical derivation of the Galerkin's formulation
} 
to a system of ordinary differential equations governing the evolution at the global nodal position, which can be written as follows:

$$
\left\{\begin{array}{l}
\mathbb{M} \underline{\hat{\boldsymbol{V}}}_{G}^{h}=\mathbb{F}^{e x t}-\mathbb{F}^{i n t}\left(\underline{\hat{\boldsymbol{U}}}_{G}^{h} ; \underline{\hat{\boldsymbol{V}}}_{G}^{h}\right)+\mathbb{F}^{\operatorname{trac}}\left(\underline{\mathcal{T}}_{G}^{h}\right) \\
\underline{\hat{\hat{U}}}_{G}^{h}=\underline{\hat{\boldsymbol{V}}}_{G}^{h}
\end{array}\right.
$$

with $\underline{\hat{U}}_{G}^{h}, \underline{\hat{\boldsymbol{V}}}_{G}^{h}$ and $\underline{\hat{\boldsymbol{A}}}_{G}^{h, n}$ the displacement, velocity global DOF vectors and $\underline{\mathcal{T}}_{G}^{h}$ the traction at the global nodes, respectively. $\mathbb{M}$ is the diagonal mass matrix (an interesting property, in terms of computational effort, inherited from the spectral discretization, and specifically from the orthogonal Lagrange polynomials employed). The vectors $\mathbb{F}^{e x t}$ and $\mathbb{F}^{i n t}\left(\underline{\hat{\boldsymbol{U}}}_{G}^{h} ; \underline{\hat{\boldsymbol{V}}}_{G}^{h}\right)$ contain the external and internal forces, respectively, and $\mathbb{F}^{\operatorname{trac}}\left(\underline{\mathcal{T}}_{G}^{h}\right)$ corresponds to the traction forces [57]. The natural diagonality of the mass matrix steers the choice of an explicit timemarching scheme, e.g. a second-order accurate leap-frog method (interpreted as a Newmark scheme as velocity-stress time-staggering, with Newmark's parameters $\alpha=0.5, \beta=0.5)$ which was found to preserve the angular momentum [58]. A CFL condition is added to grant numerical stability (classical Courant's number varies between 0.15 to $0.2[59,57])$.

Internal forces $\mathbb{F}^{i n t}\left(\underline{\hat{U}}_{G}^{h} ; \underline{\hat{\boldsymbol{V}}}_{C}^{h}\right)$ are computed based on the visco-elastic rheological model proposed in [60], i.e. the generalized Zener model [61], which accurately mimics the mechanical behavior of classical viscoelastic media during relaxation experiments.

Finally, external forces by numerical discretization of the point-wise seismic source, generally represented by a spatial distribution of body forces with zero resultant force and moment, in agreement with the internal origin of earthquakes [30]. A simple and powerful way of representing seismic sources is via the seismic moment tensor density [62], and the corresponding equivalent body force distribution [43]. The point-wise forces are integrated by approximating the Dirac's delta with normalized shape function centered on the source location.

To be able to model the wave-propagation problem in a full/half space, some 


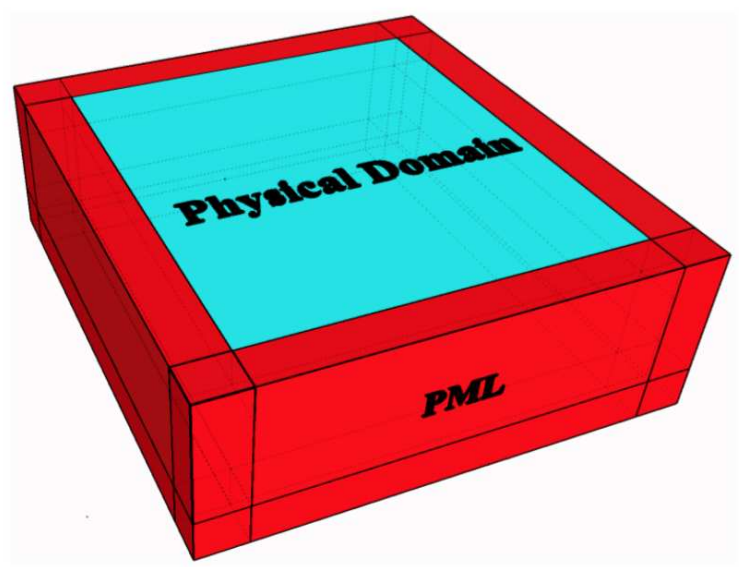

Figure C.16: A half space domain surrounded by PML materials (courtesy of [57])

absorbing boundary conditions are routinely employed. An efficient absorbing boundary condition has been mediated from electro-magnetism [63] and applied to computational seismology [32]: the Perfect Matched Layers (PML) is herein applied to the SE formulation. PML is an absorbing medium that envelopes the computational domain so to absorb the wave-field impinging the domain truncation surface (see Figure C.16). In a wider sense, a PML corresponds to an imaginary extension of the real physical space. This extension of the spatial coordinates to the complex space is obtained by the following coordinate change [32] :

$$
\tilde{x}=x+\frac{\Sigma(x)}{i \omega}
$$

where $\omega$ is the circular frequency and $\Sigma(x)$ is an arbitrary function of $x$ which increases regularly from the interface of the domain of interest to the external border of the PML. In turns, for a plane-wave written in the form of:

$$
\mathbf{\Phi}(x, z, t)=\mathbf{A} e^{i\left(\omega t-k_{x} x-k_{z} z\right)}
$$


where $A$ is the amplitude and $k_{x}$ and $k_{z}$ are respectively the wave numbers in $x$ and $z$ directions, will be transformed in the PML in $x$ direction as:

$$
\tilde{\boldsymbol{\Phi}}(x, z, t)=\boldsymbol{\Phi}(x, z, t) e^{-\frac{k_{x}}{\omega} \Sigma}
$$

which decreases exponentially independently of frequencies because of the ratio $\frac{k_{x}}{\omega}$. Consider the decomposition in plane-wave of an Rayleigh wave propagating along the free surface $\left(z=z_{\max }\right)$. The dependence along $x$ direction of that wave will have the same characteristics as those of volume waves: they respect the same decreasing properties when they enter into the PML in $x$ direction. Additionally, they preserve the characteristics of a surface wave, i.e. the movement is characterized by an exponential decreasing with the depth and an elliptic retrograde polarization in the propagation plane on the surface, and prograde in the depth. The classical choice of transformation in PML domain, as indicated in C.3 allows for a uniform decay, independent of frequencies inside the absorbing layer PML and a simplified description of the motions. More sophisticated expressions can lead to just as simple representations in the time domain, with interesting properties inside the PML. If a real part is added to the frequency term, the pole of the stretching is moved away from the origin of the reference frame, into the imaginary axis, and the transformation can be written as:

$$
\tilde{x}=x+\frac{\Sigma(x)}{i \omega+\omega_{c}}
$$

With this transformation, the compressional waves decrease in the PML following :

$$
\tilde{\mathbf{\Phi}}(x, z, t)=\boldsymbol{\Phi}(x, z, t) e^{-\frac{k x}{\omega} \frac{\omega^{2}-i \omega \omega_{c}}{\omega^{2}+\omega_{c}^{2}} \Sigma}
$$

where $\omega_{c}$ is for instance, the circular cut-off frequency. The transformation is finally dependent of frequencies through the factor $\frac{\omega^{2}-i \omega \omega_{c}}{\omega^{2}+\omega_{c}^{2}}$. Its real part contributes to the changes of the amplitude of decay, while its imaginary part is responsible of a phase shift. 
Appendix D. Dynamic Soil Structure Interaction problem: theory and numerical resolution

Appendix D.1. Physical and Mathematical problem

For the sake of clarity, whenever the SSI problem is tackled, the overall domain is decomposed in three sub-parts, namely: the unbounded soil $\Omega_{s}$, the bounded foundation $\Omega_{f}$ and the bounded structure $\Omega_{b}$ (see FigureD.17). In this

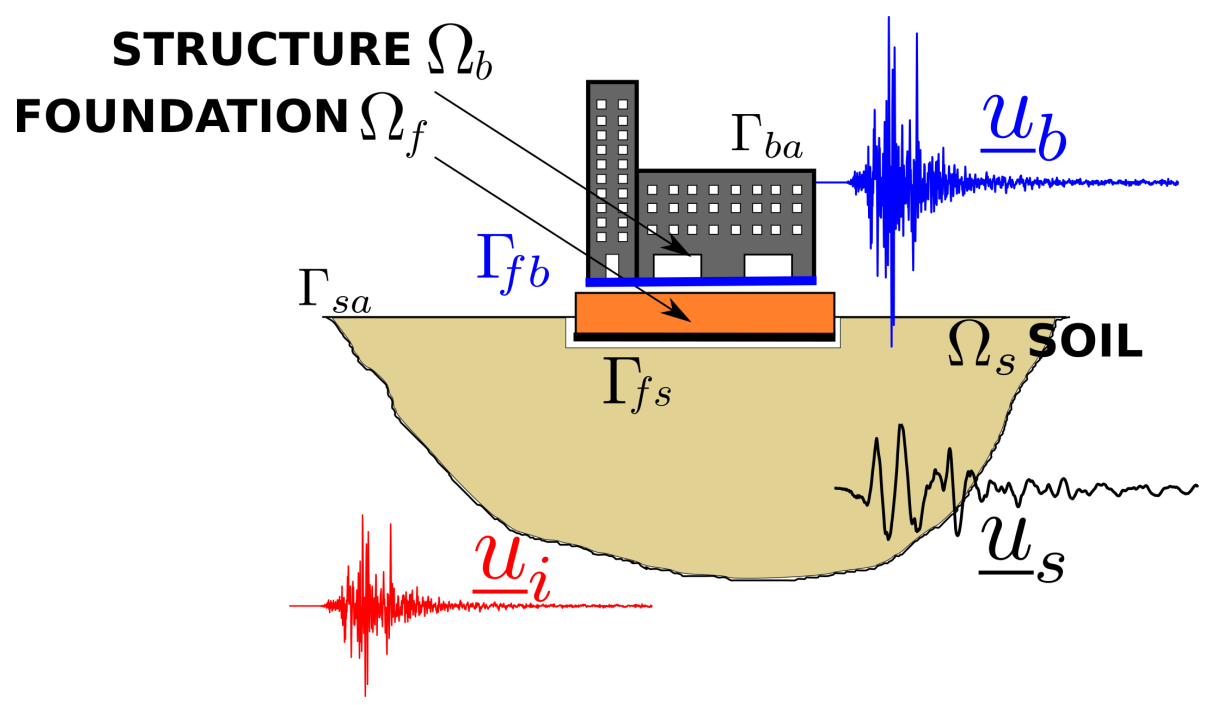

Figure D.17: Scheme of the SSI problem.

case, the sought elastodynamics solutions are the dynamic perturbations due to the incident ground motion $\underline{\boldsymbol{u}}_{i}(\underline{\boldsymbol{x}} ; t)$ (an elastodynamics field), i.e. $\underline{\boldsymbol{u}}_{s}(\underline{\boldsymbol{x}} ; t)$ and $\underline{\boldsymbol{u}}_{b}(\underline{\boldsymbol{x}} ; t)$ for soil and superstructure respectively. Moreover, those wave-field comply with the traction-free condition at the free surfaces $\Gamma_{s a}$ (soil) and $\Gamma_{b a}$ (structure) respectively. In this framework of the substructure approximation, by applying the virtual work principle to the superstructure $\Omega_{b}$ and to the foundation $\Omega_{f}$, it is possible to obtain the discretized system of equations of motion, in the frequency domain:

$$
\left[\begin{array}{cc}
\mathbb{K}_{b}+i \omega \mathbb{C}_{b}-\omega^{2} \mathbb{M}_{b} & -\omega^{2} \mathbb{M}_{c} \\
-\omega^{2} \mathbb{M}_{c}^{T} & \mathbb{K}_{s}(\omega)-\omega^{2} \mathbb{M}_{f}
\end{array}\right]\left\{\begin{array}{l}
\hat{\underline{\boldsymbol{q}}}_{b} \\
\underline{\hat{\boldsymbol{q}}}_{f}
\end{array}\right\}=\left\{\begin{array}{c}
0 \\
\underline{\boldsymbol{f}}_{f}
\end{array}\right\}
$$


with $\mathbb{K}_{b}, \mathbb{C}_{b}$ and $\mathbb{M}_{b}$ being stiffness, damping and mass matrices for the superstructure, $\mathbb{K}_{s}(\omega)$ the soil impedance stiffness (defined on the soil-foundation interface nodes), $\mathbb{M}_{f}$ the foundation mass matrix (defined on all the foundation nodes), $\mathbb{M}_{c}$ the adjoint mass matrix and $\underline{\boldsymbol{f}}_{f}$ the resultant force at $\Gamma_{f s}$ (defined on the soil-foundation interface nodes), i.e. the induced seismic forces introduced at the foundation level. The sought solution is the set of participation factors $\underline{\boldsymbol{q}}_{f}$ and $\underline{\boldsymbol{q}}_{b}$ of foundation and structure respectively.

$$
\begin{aligned}
& \underline{\hat{\boldsymbol{u}}}_{d}(\underline{\boldsymbol{x}} ; \omega)=\underline{\hat{\boldsymbol{u}}}_{f}(\underline{\boldsymbol{x}} ; \omega)-\underline{\hat{\boldsymbol{u}}}_{i}(\underline{\boldsymbol{x}} ; \omega), \quad \forall \underline{\boldsymbol{x}} \in \Gamma_{f s} \\
& \underline{\hat{\boldsymbol{u}}}_{d}(\underline{\boldsymbol{x}} ; \omega)=\sum_{m=1}^{6} \underline{\hat{\boldsymbol{u}}}_{d, m}(\underline{\boldsymbol{x}} ; \omega)+\underline{\hat{\boldsymbol{x}}}_{d 0}(\underline{\boldsymbol{x}} ; \omega), \quad \forall \underline{\boldsymbol{x}} \in \Gamma_{f s}
\end{aligned}
$$

where $\underline{\hat{\boldsymbol{u}}}_{0}(\underline{\boldsymbol{x}} ; \omega)$ is the displacement due to local diffraction of the incident wave field and $\underline{\hat{\boldsymbol{x}}}_{d, m}$ the radiation caused by a unitary foundation movement. The latter components solve the following equations:

$$
\begin{aligned}
& \underline{\boldsymbol{\nabla}}_{x} \cdot \underline{\underline{\boldsymbol{\sigma}}}\left[\underline{\hat{\boldsymbol{u}}}_{d 0}\right]+\rho \omega^{2} \underline{\hat{\boldsymbol{\mu}}}_{d 0}=\underline{\mathbf{0}}, \quad \forall \underline{\boldsymbol{x}} \in \Omega_{s} \\
& \underline{\hat{\boldsymbol{u}}}_{d 0}=-\underline{\hat{\boldsymbol{u}}}_{i}, \quad \forall \underline{\boldsymbol{x}} \in \Gamma_{f s} \\
& \underline{\boldsymbol{\nabla}}_{x} . \underline{\underline{\boldsymbol{\sigma}}}\left[\underline{\hat{\boldsymbol{u}}}_{d, m}\right]+\rho \omega^{2} \underline{\hat{\boldsymbol{u}}}_{d, m}=\underline{\mathbf{0}}, \quad \forall \underline{\boldsymbol{x}} \in \Omega_{s} \\
& \underline{\hat{\boldsymbol{u}}}_{d, m}=\underline{\boldsymbol{\psi}}_{f}^{m}, \quad \forall \underline{\boldsymbol{x}} \in \Gamma_{f s}
\end{aligned}
$$

Finally, the dynamic impedance of the soil $\mathbb{K}_{s}(\omega)$ reads:

$$
\mathbb{K}_{s[m, n]}(\omega)=\int_{\Gamma_{f s}} \underline{\boldsymbol{t}}_{n}\left[\underline{\hat{\boldsymbol{\mu}}}_{d, m}\right] \cdot \underline{\boldsymbol{\psi}}_{n} d S, \quad m, n=1,6
$$

and the induced seismic forces $\underline{\boldsymbol{f}}_{f}$ read:

$$
\underline{\boldsymbol{f}}_{f}=-\int_{\Gamma_{f s}} \underline{\boldsymbol{t}}_{n}\left[\underline{\hat{\boldsymbol{u}}}_{i}+\underline{\hat{\boldsymbol{t}}}_{d 0}\right] \cdot \underline{\boldsymbol{\psi}}_{m} d S, \quad m=1,6
$$

where $\underline{\psi}_{m}$ are the rigid-body motions of the rigid foundation. 
Appendix E.1. Soil properties at RBY building

Table E.5: Soil properties nearby the reactor building RB7. T.M.S.L.: Tokyo Mean Sea Level.

\begin{tabular}{rrrrrrr}
\hline $\begin{array}{r}\text { Altitude } \\
\text { T.M.S.L. }[\mathrm{m}]\end{array}$ & Soil & $V_{S}$ & $V_{P}$ & $\rho$ & $\nu$ & $\mathrm{G}$ \\
+12.0 & Type & {$[\mathrm{m} / \mathrm{s}]$} & {$[\mathrm{m} / \mathrm{s}]$} & {$\left[\mathrm{kg} / \mathrm{m}^{3}\right]$} & {$[1]$} & {$[\mathrm{kPa}]$} \\
+8.0 & Sable & 150 & 310 & 1610 & 0.347 & 36000 \\
+4.0 & Sable & 200 & 380 & 1610 & 0.308 & 65700 \\
-6.0 & Clay & 330 & 1240 & 1730 & 0.462 & 192000 \\
-33.0 & Rock & 490 & 1640 & 1700 & 0.462 & 416000 \\
-90.0 & Rock & 530 & 1660 & 1700 & 0.446 & 475000 \\
-136.0 & Rock & 590 & 1710 & 1730 & 0.432 & 614000 \\
-155.0 & Substratum & 720 & 1900 & 1990 & 0.416 & 1050000 \\
\hline
\end{tabular}

Appendix E.2. Modal analysis of the RB7 building FEM structural model

The modal analysis of of the fixed-base model numerical model of the RB7 building was performed within the framework of the KARISMA benchmark [23]. The results obtained are given in Table

Table E.6: Results of the modal analysis performed on the rigid fixed base RB7 building [23].

\begin{tabular}{lllllll|cccc}
\hline & \multicolumn{3}{c}{$f_{N}[H z]$} & \multicolumn{4}{c}{$\begin{array}{l}\text { Modal participating } \\
\text { mass ratios (\%) }\end{array}$} & $\begin{array}{c}\text { Total Mass } \\
\text { [ton] }\end{array}$ & \multicolumn{2}{c}{ Total mass in } \\
$f_{X}$ & $f_{Y}$ & $f_{Z}$ & $U_{X}$ & $U_{Y}$ & $U_{Z}$ & $M_{T O T}$ & $M_{X}$ & $M_{Y}$ & $M_{Z}$ \\
\hline 4.08 & 4.54 & 8.94 & 42.7 & 53.3 & 3.7 & 199411 & 68.0 & 68.0 & 57.0 \\
\hline
\end{tabular}

